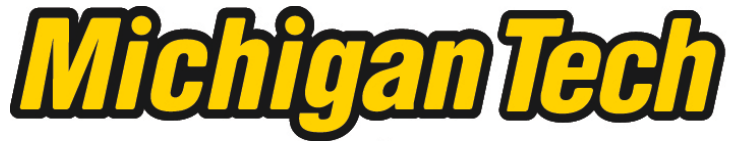 \\ Michigan Technological University Create the Future Digital Commons @ Michigan Tech
}

Dissertations, Master's Theses and Master's Reports - Open

Dissertations, Master's Theses and Master's

Reports

2007

Real-world context, interest, understanding, and retention

Annikka Chrestensen

Michigan Technological University

Follow this and additional works at: https://digitalcommons.mtu.edu/etds

Part of the Science and Mathematics Education Commons

Copyright 2007 Annikka Chrestensen

\section{Recommended Citation}

Chrestensen, Annikka, "Real-world context, interest, understanding, and retention", Master's report, Michigan Technological University, 2007.

https://doi.org/10.37099/mtu.dc.etds/536

Follow this and additional works at: https://digitalcommons.mtu.edu/etds

8 Part of the Science and Mathematics Education Commons 


\title{
Real-World Context, Interest, Understanding, and Retention
}

\author{
By \\ Annikka Chrestensen \\ A Research Report submitted in partial fulfillment of the \\ Requirements for the degree of \\ MASTER OF SCIENCE IN APPLIED SCIENCE EDUCATION \\ Through \\ The Department of Education
}

Michigan Technological University

August 2007

Copyright (C) Annikka Chrestensen 2007 
(This page is deliberately blank) 
This research report "Real-World Context, Interest, Understanding, and Retention" is hereby approved in partial fulfillment of the requirements for the degree of Master of Science in Applied Science Education.

DEPARTMENT or PROGRAM:

Department of Education

$\begin{array}{cl}\text { Signatures: } & \\ \text { Thesis Advisor } & \\ \text { William L. Yarroch } \\ \text { Department Chair } & \\ & \text { Brad Baltensperger }\end{array}$

Date 
(This page is deliberately blank) 


\begin{abstract}
This study investigated the use of real-world contexts during instruction in a high school physics class - through building file folder bridges- and the resulting effect upon student interest in the subject matter, level of understanding, and degree of retention. In particular, the study focused upon whether increases in student interest were attained through the use of real-world contexts, and if the elevated interest level led to a higher degree of subject matter understanding than would be achieved using more traditional teaching methods. The study also determined whether using real-world contexts ultimately resulted in achievement of greater levels of knowledge retention by students.

Class observations during traditionally taught units and during units that incorporated real-world contexts, along with a post-graduation questionnaire, were used to assess differences in student interest levels. Student pre- and post-unit test scores were evaluated and compared to determine if statistical differences existed in levels of understanding resulting from the different teaching methods. The post-graduation questionnaire results provided evidence of retention that could be related back to teaching methods.

The results of this study revealed the importance of incorporating real-world contexts into science and mathematics courses. Students better understood the relevance of the lessons, which led to higher levels of interest and greater understanding than was achieved through more traditional teaching methods. The use of real-world contexts improved knowledge retention.
\end{abstract}


(This page is deliberately blank) 


\section{Acknowledgements}

I would like to thank everyone at Atherton High School and all of my students who completed my questionnaire. I'm sure each of you never thought you would do more work regarding my class after you graduated! Keep in touch!

I would also like to thank my family for encouraging me to finish this paper when I wanted to quit. Thank you Jed for helping me with proofreading and general support. Kaisa, Keira, and Jordan, thank you for being such great kids and for being quiet while I worked, at least some of the time.

Finally I would like to thank Dr. Yarroch for correcting my paper and helping me fix my mistakes. I'm glad you never said throw it out and start over, even though by now I probably have done that with so many revisions. I don't know how you can read so many of these papers so many times.

Thank you everyone, Annikka 
(This page is deliberately blank) 


\section{Table of Contents}

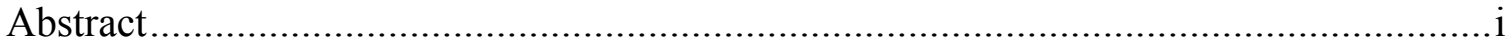

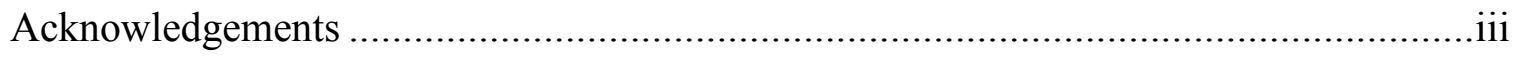

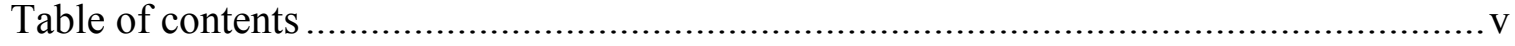

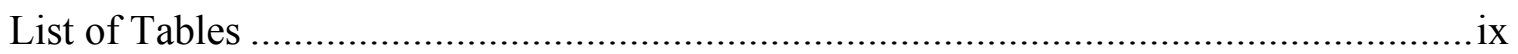

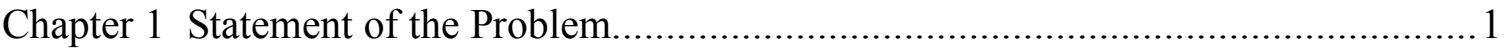

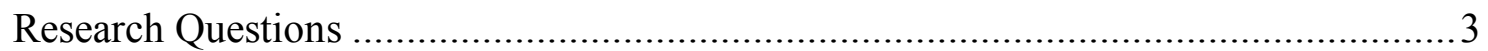

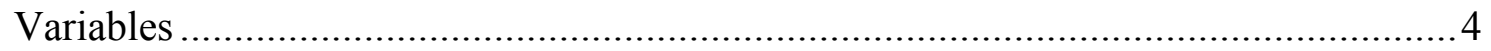

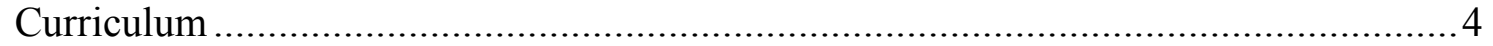

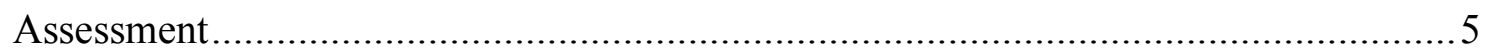

Chapter 2 Literature Review ................................................................... 7

Real-World Contexts .................................................................................... 7

Interest and Subject Matter in Real-World Contexts ........................................ 10

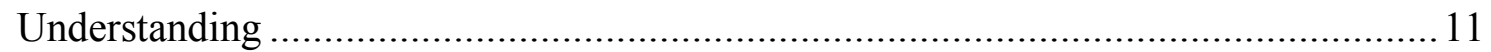

Retention of Knowledge ........................................................................ 14

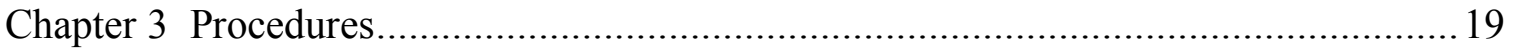

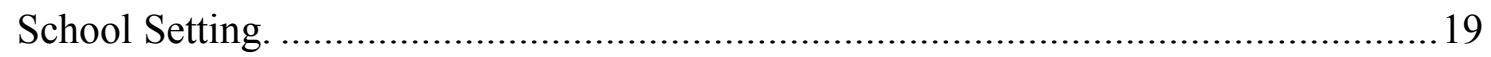

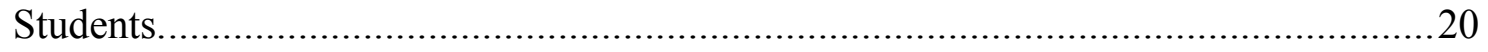

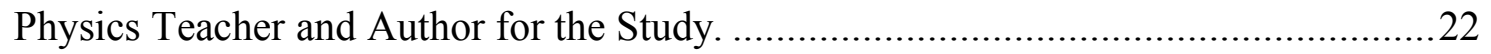

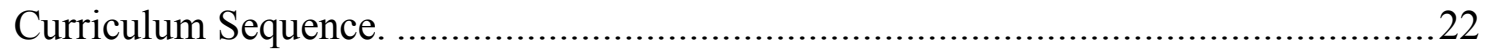

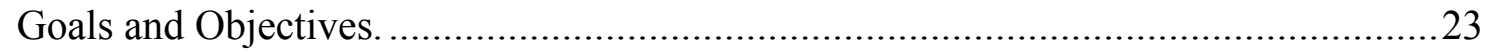

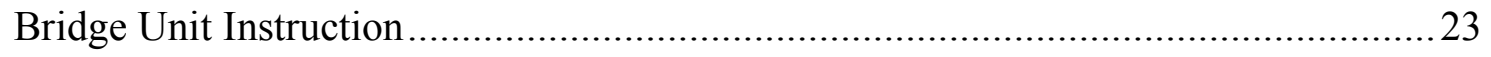

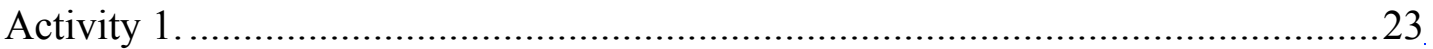




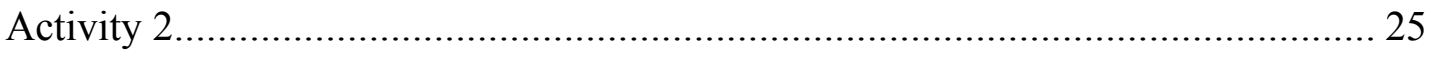

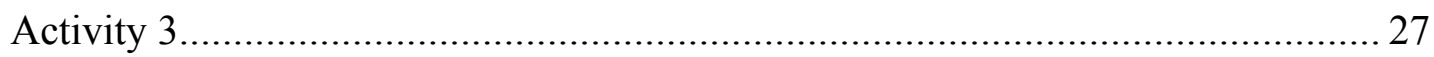

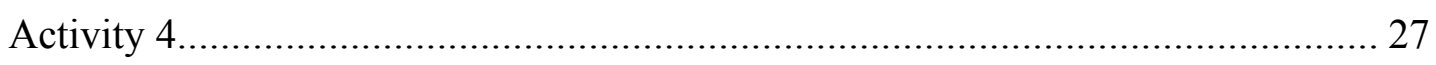

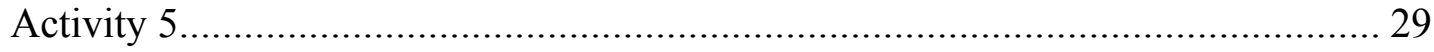

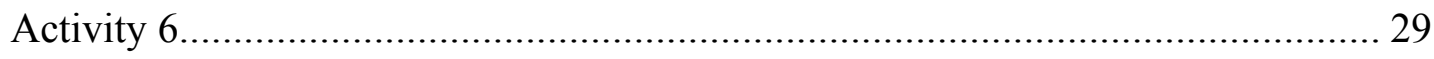

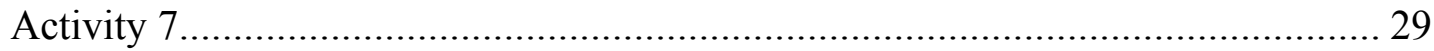

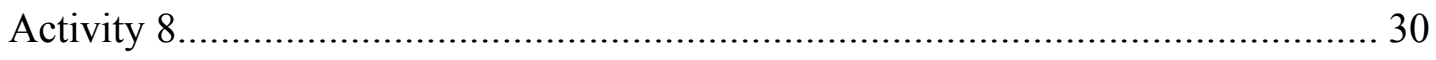

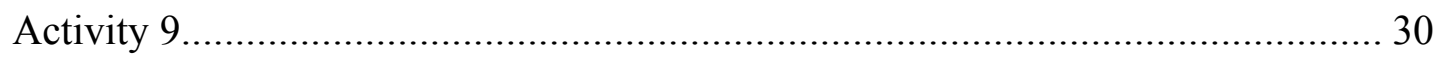

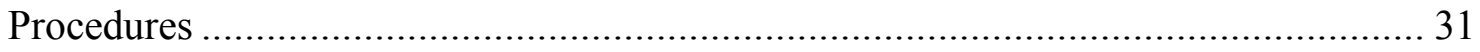

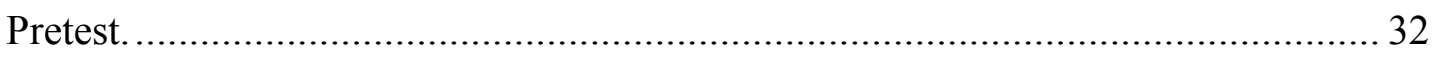

Embedded Assessment. ................................................................................. 32

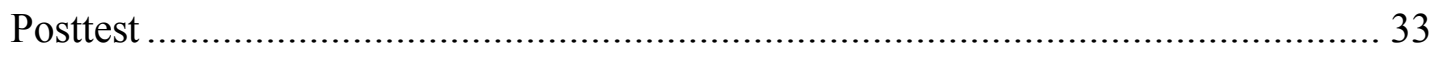

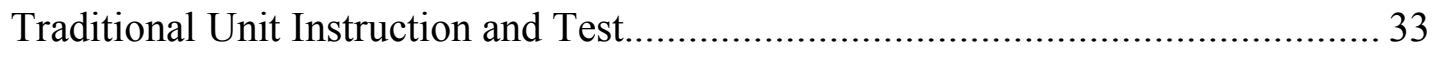

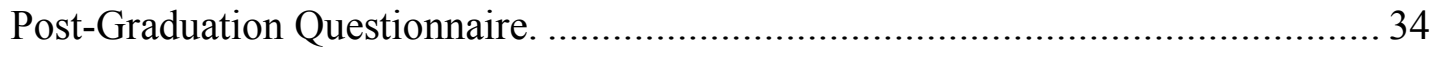

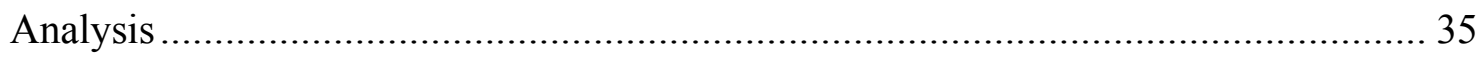

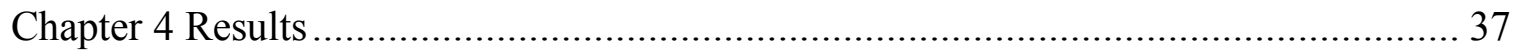

Post-Graduation Questionnaire Sample .................................................... 37

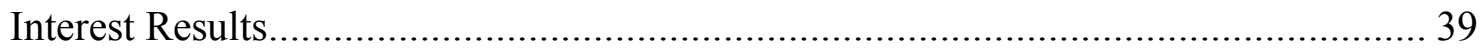

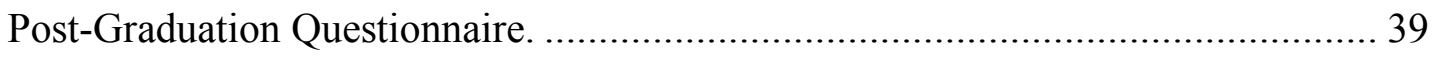

Anecdotal Observations of Twelve Students ............................................ 40

Other General Comments for all 34 Students .............................................. 45

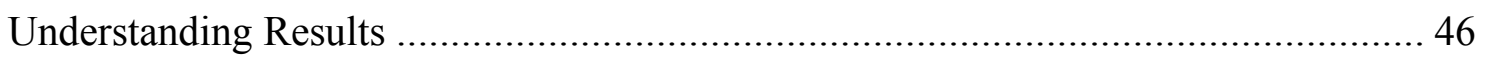

Pretest versus Posttest ........................................................................ 46 
Posttest versus Traditional Unit Test .............................................................. 46

Student Responses Regarding Understanding ............................................... 48

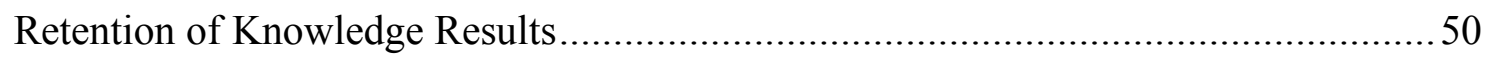

Pretest versus Post-Graduation Questionnaire.....................................................50

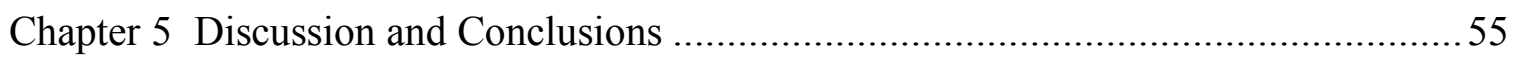

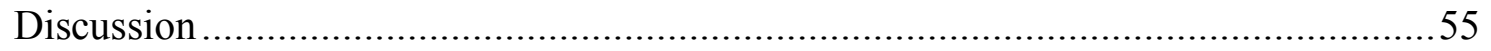

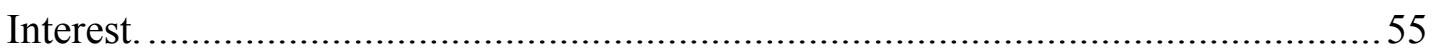

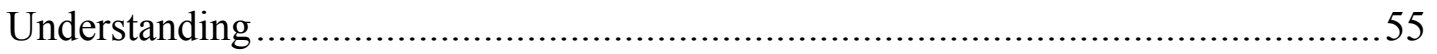

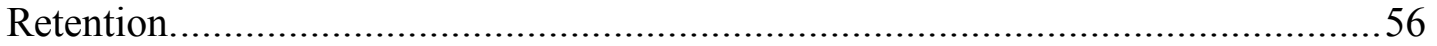

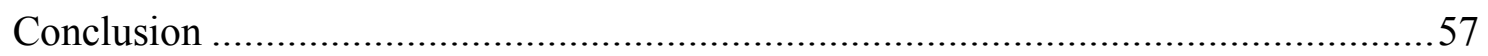

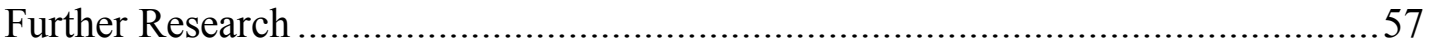

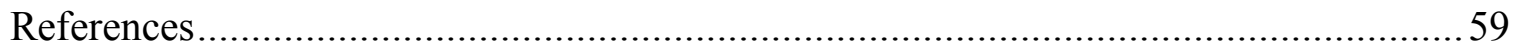

Appendix A. Michigan Depart. of Ed. Standards and Benchmarks for High School .... 63

Appendix B. Unit Activities, Handouts, and Surveys ......................................6 65

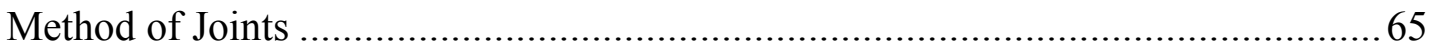

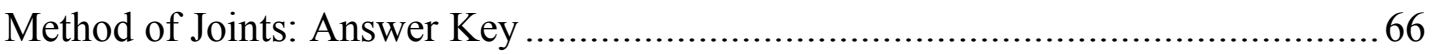

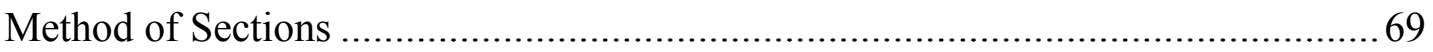

Method of Sections: Answer Key .................................................................... 70

Appendix C. Handouts for Students ....................................................... 73

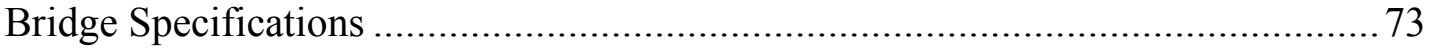

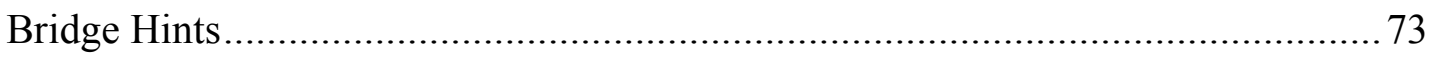

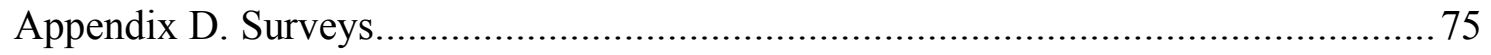

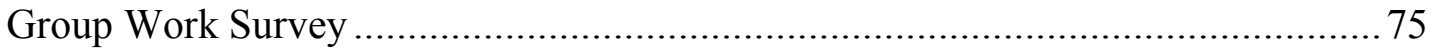




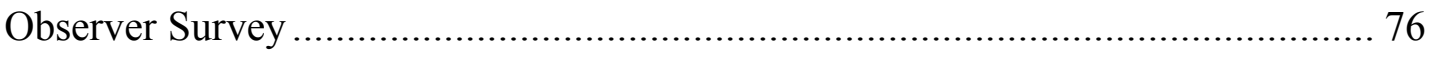

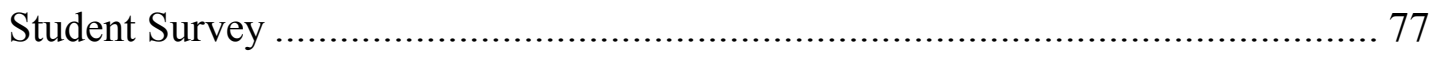

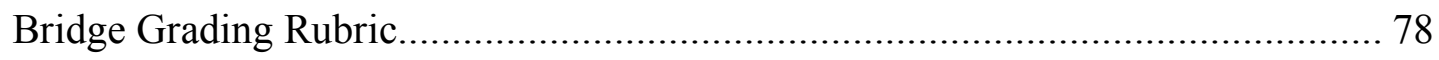

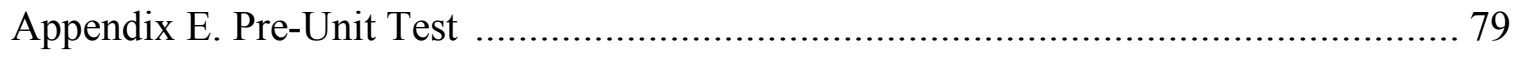

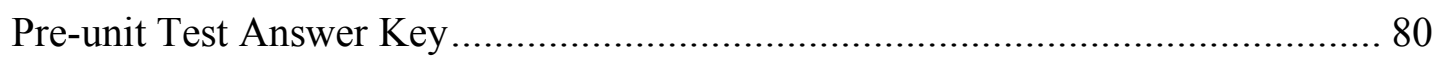

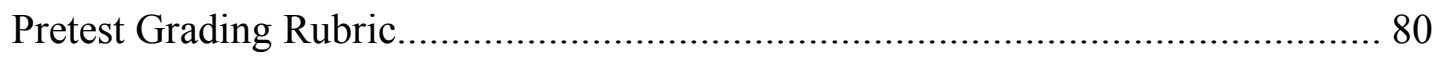

Appendix F. Bridge Unit Posttest .......................................................................... 81

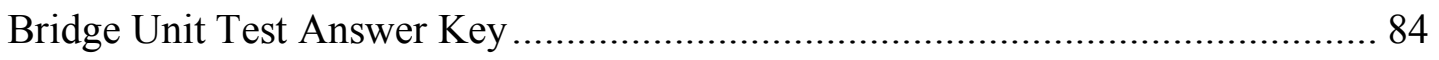

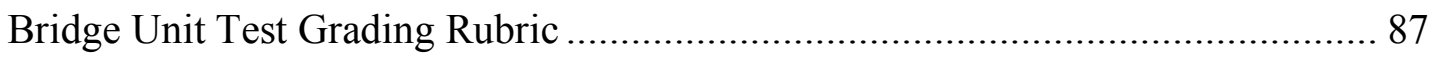

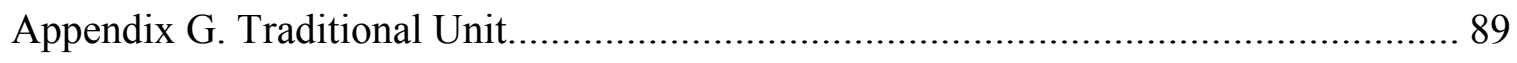

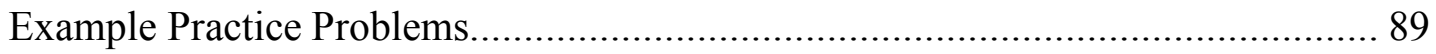

Practice Problems Answer Key ....................................................................... 90

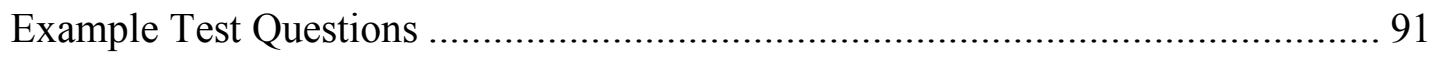

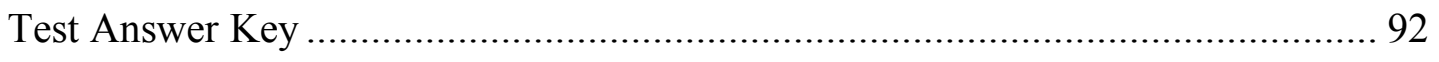

Appendix H. Post-Graduation Questionnaire................................................................... 93

Post-Graduation Questionnaire-Answer Key for questions 23, 24, 25, 26, \& 27 ..... 94

Post-Graduation Questionnaire Grading Rubric ……………................................... 94

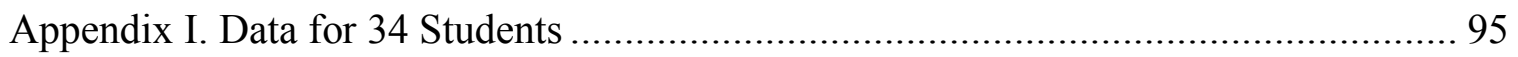




\section{List of Tables}

Table 1. Free and Reduced Lunch Statistics for Atherton.................................... 21

Table 2. Graduation Rates for State of Michigan and Atherton High School .............. 21

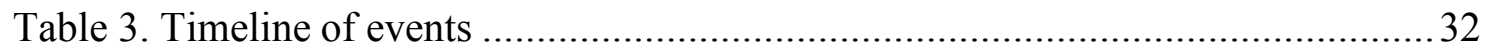

Table 4. Distribution of Students from Post-Graduation Questionnaire ........................38

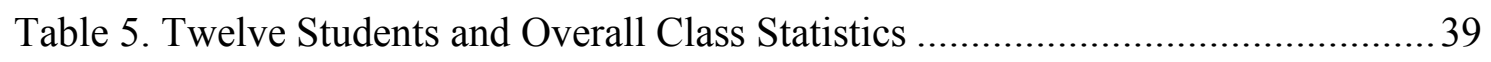

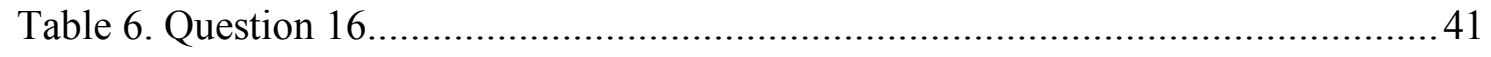

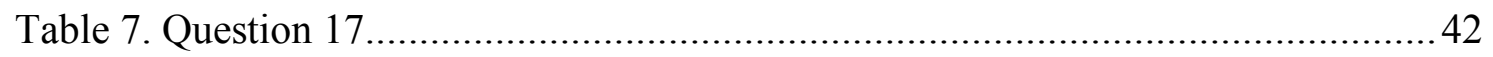

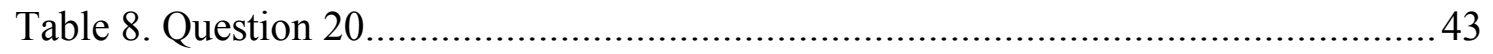

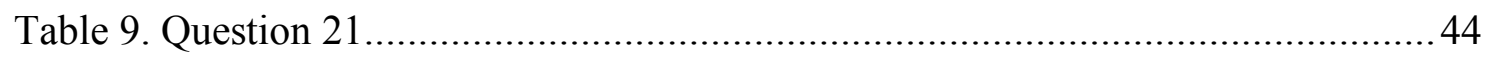

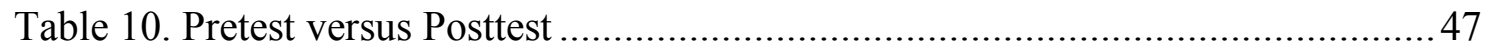

Table 11. Bridge Unit Posttest and Traditional Unit Test Data ................................49

Table 12. Results of post-graduation questionnaire ...................................... 51

Table 13. Pretest and Post-graduation Questionnaire Data ...................................52

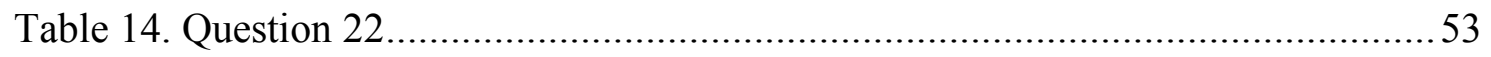


(This page is deliberately blank) 


\section{Chapter 1}

\section{Statement of the Problem}

I began teaching mathematics and physics at Atherton High School in the fall of 2000. Atherton is one of three high schools in the City of Burton, a suburb of Flint, Michigan. Most of my students were raised in families where one or both parents worked in the local factories. These students planned on following in their parents' footsteps and really felt as though they had no use for the math and science that I was teaching to them. Bouillion and Gomez's (2001) observation that “teaching and learning are often disconnected from the day-to-day life of the community, and students don't see how the skills they acquire in school have currency in business, at home, and in other communities beyond school” (p. 878) rang true. Unfortunately many of the plants and factories in the Flint/Burton area have either been downsized or closed. I saw this sad fact as a pressing reason to motivate my students and increase their understanding of math and science. I felt as though they needed to be prepared for career paths that would require more math and science than would be required in the local factories. The unemployment rate for Flint, Michigan in Genesee County was roughly $8.3 \%$ as reported by the Michigan Department of Labor and Economic Growth (2007). I was constantly trying to find ways to show my students how important math and science were and what job opportunities were available.

Teachers are faced with the pressure of preparing their students for an increasingly competitive modern world, yet many students are not developing the math and science skills they need to succeed. "American students generally perform less well in math and science as they move through school, when compared to other industrialized 
countries. Our fourth-graders are above the international average, while our twelfthgraders are near the bottom" (U.S. Department of Education (U.S. Dept. of Ed.)), 2004, p.40).

Students need strong mathematic and scientific skills to be prepared for technical positions. It was reported by Loston, Steffan, and McGee (2005), that, even NASA has had problems finding replacements for people retiring from scientific and technical careers. The demand for math and science can be seen in the United States, as noted by the National Science Board in Science and Engineering Indicators, "the number of jobs requiring science and engineering skills in the U.S. labor force is growing almost 5\% per year" (as cited in Loston, et al. 2005, p.148). This growth rate is equivalent to the resident population growth of 5\% in the United States between the years 2000 and 2005 as reported by the U.S. Census Bureau (2006). "According to the Bureau of Labor Statistics, jobs requiring science, engineering or technical training will increase 24 percent between 2004 and 2014...” (U.S. Dept. of Ed., 2006, para. 2). Bybee and Juchs (2006) agree that the U.S. needs people with strong scientific and technological backgrounds in the workforce and all students need to be scientifically literate.

The No Child Left Behind Act is also pushing teachers to find new and better ways of teaching math and science (U.S. Dept. of Ed., 2004). If teachers are to address the need for students to be better equipped with these skills, Scherz and Oren (2006) believe that teachers need to help students see the connection between school and authentic science and technological practice through realistic investigations.

I took ENG5100, The Engineering Process, at Michigan Technological University in the summer of 2002. Teachers are introduced to engineering principles in this course. 
The course was designed to help teachers bring engineering principles into the classroom and potentially get more students to understand and be interested in math and science by incorporating these principles in their teaching. I found the bridge building portion of the class, where techniques for designing and calculating forces on bridges were taught, to be particularly interesting and decided that it was something I could use in my classroom to help engage my students and increase their interest and understanding of math and science.

I am always looking for new and better ways to teach math and science concepts to my students and I thought that incorporating engineering principles would help increase my students' understanding. The use of forces in two dimensions is a large part of designing and building bridges, at least bridges constructed of manila file folders. The concept of two-dimensional forces is a subject that my physics students sometimes struggled with. Moje, Collazo, Carrillo, and Marx (2001) felt that one way to engage all students is through project-based instruction. Bouillion and Gomez (2001) believed that students need to see how school and life are related. It seemed perfect to me to use something all of the students could relate to - bridges, to focus on an area of physics that was challenging to students and make it fun, and interesting.

\section{Research Questions}

The research questions I focused on in this study included the following:

1. Does the use of real-world contexts increase student interest?

2. Does interest in subject matter promote understanding?

3. Do students retain concepts that are taught using real-world contexts? 


\section{Variables}

Interest: The amount of excitement and curiosity created by new experiences. The interest level in the unit was measured through port-graduation questionnaire of students.

Real-World Contexts: The use of real-world ideas, activities and lessons to facilitate learning.

Understanding: The ability to use, interpret, apply, explain, and solve problems using new and previously known knowledge. This was measured using a pre- and posttest, lab write-up, and through designing, constructing, and testing bridges.

Retention: The process of placing information into memory. The ability to keep information in memory for a time period that is longer than that necessary to just take and pass a test. This was measured through a post-test, end of the year exam, and a post-graduation questionnaire.

\section{Curriculum}

The Michigan Department of Education's Content Standards for High School Mathematics and Science (Michigan Department of Education, 1996) include benchmarks that require students to measure, analyze data, and design and conduct 
scientific investigations. The implementation of the bridge unit does not interfere with the requirements of the curriculum for physics, which includes the MDE standards and benchmarks. Many of the MDE benchmarks are met during the bridge unit (Appendix A).

\section{Assessment}

Students were assessed through a variety of methods during the bridge unit, including pre- and posttests, activities, assignments, personal observations, and a postgraduation questionnaire. This study specifically discusses the assessments of:

1. Interest, through observations and a post-graduation questionnaire.

2. Understanding, through pre- and posttests with comparisons made to a traditionally taught unit.

3. Retention, through a pretest and a post-graduation questionnaire. 
(This page is deliberately blank) 


\section{Chapter 2}

\section{Literature Review}

A number of research studies have been conducted on the use of real-world contexts in the classroom. This research examined the effect of real-world contexts during instruction on the level of student interest in the subject matter, students' understanding of subject matter, and retention of knowledge. This literature is reviewed below.

\section{Real-World Contexts}

Scherz and Oren (2006) looked at drawings done by six classes of $8^{\text {th }}$ and $9^{\text {th }}$ grade students from three schools before and after the students were involved with an Investigation into Science and Technology (IST) program. The program lasted two months and was broken into 3 to 4 hour weekly classes. The students visited various laboratories and/or technological sites. The students were able to observe and interview professionals, have exposure to advanced experimentation - as done by professionals in the field - and up-to-date equipment, and get involved in activities at the laboratories and technological sites. The site visitation allowed students to get a real-world view and the chance to "get acquainted with the new environment - physically, socially, and in terms of knowledge, working methods, and human interactions" (Scherz and Oren, 2006, p. 970). The information and data that Scherz and Oren gathered showed that a greater percentage of students in their study had more accurate and realistic views of scientific and technological sites and the people who work there after the laboratory and technological site visits. Due to the results of their research, Scherz and Oren (2006) 
concluded that teachers need to incorporate meaningful and authentic experiences with real-world science and technology into their science classrooms.

Wu (2003) studied twenty-five $11^{\text {th }}$ grade students, who worked in small groups, at a small high school. The students in Wu's study were taught science in the context of local topics and real issues with practical applications during a three-year integrated science program, called Foundations of Science (FOS). An example of an FOS topic that the students in Wu's research worked on was determining if their water was safe to drink. $\mathrm{Wu}$ (2003) observed that in this type of learning environment, real-life situations make the concepts students learn meaningful. Observations made during classroom discussions between students and teachers led $\mathrm{Wu}$ to believe that through FOS students were able to see that science is "not a special kind of truth" (Wu, 2003, p. 888), and that an experience such as this allows students to see how classroom science lessons relate to and can be linked to their lives.

Bouillion and Gomez (2001) studied two self-contained classes of $5^{\text {th }}$ grade students in Chicago as they worked on a real-world problem in the community called the Chicago River project. This project was chosen by the students and involved the clean up of a local riverbank which was polluted. The students wrote letters to local businesses and surveyed members of the community. Bouillion and Gomez focused on how varied types of scientific concepts can be used to advance student learning, with an emphasis on learning in urban areas. They explained that the project allowed school and community to come together to promote learning. Data for the study was collected through observations, field notes, student artifacts, and pre- and post-instruction interviews with teachers and students. Student responses to questions, posed by teachers, demonstrated 
an understanding of scientific concepts such as systems and cycles. The researchers also found evidence, through the students' conversations and activities, that the students demonstrated that they had learned concepts such as water quality, and soil erosion. The teachers in the study reported that the students also had improved their "ability to access information, form questions, share ideas, and analyze and compare data" (Bouillion \& Gomez, 2001, p. 888).

Schneider, Krajcik, Marx, and Soloway (2002) studied Problem Based Science (PBS) through a FOS program at a small alternative high school. Students in the program studied broad driving questions, worked on projects that lasted several weeks, and integrated the sciences: earth, biology, chemistry, and ecology. Schneider et al. wanted to determine if students involved in PBS would score as well as students nationally on achievement test items. Their study showed that the:

...PBS students performed higher than the national sample on most of the scientific investigation questions. ....[The students] appear to acquire as much or more conceptual understanding as students nationally. ....[The students] did score higher in science than students at schools offering advanced placement courses, which lends support to the PBS science program at this school. (Schneider et al., 2002, p. 420).

These studies of real-world contexts show how authentic real-world experiences help to ensure students have realistic views of science and technology. Student learning can be enhanced through real-world projects in the classroom or community. Real-world contexts help students see the importance of science in their lives and at the same time increase their comprehension of science concepts. 


\section{Interest and Subject Matter in Real-World Contexts}

McCarthy (2005) found that middle school students understand more information, have more positive attitudes, and also perform better on tasks when they are involved in hands-on activities. McCarthy studied two self-contained classrooms, each with nine junior high students who were "seriously emotionally disturbed". Both classes were given three pretests: multiple choice, short answer, and hands-on. Each class was then given instruction of the same topic, one through book instruction and the other through hands-on instruction (which did not include real-world contexts). It was found that the students who had the hands-on instruction "performed significantly better on measures of achievement..." (McCarthy, 2005, p. 255) than the textbook instruction group. Although it was not actually measured, the teaching assistants in the study verbally reported that the students were interested in the material, paid attention, and participated in activities and class discussions. McCarthy suggested that activity-centered science enhances understanding and generates positive attitudes toward science.

Vasilia Cristidou conducted a study concerning students interest and experiences in science that involved 583 Greek ninth grade students from 27 schools. The students were given questionnaires by their teachers regarding topics they were interested in ( 81 questions were used for the study) and their out-of-school science-related experiences (45 questions were used for the study) (Christidou, 2006). Data collected through these questionnaires led Christidou to conclude that for instruction to be meaningful, students' life experiences and interests should be included. Christidou found that there were differences in what topics were taught in schools and what topics were of interest to students, which was different for boys versus girls. The researcher suggested that "there 
is considerable common ground in the Greek girls' and boys' interests in which a future curriculum reform could invest in order to support the students' interest in science and, at the same time, reduce relevant gender differences" (p. 1194).

A study was done on improving students' attitudes in science through the use of the Faulkes Telescopes (Beare, 2007). The Faulkes telescopes are two research quality telescopes; one based in Hawaii, the other in Australia, to ensure night viewing during daytime hours in the United Kingdom where the Faulkes Telescope Project was developed. A team was organized to develop the project, it was thought that the best use of the telescopes would be through real investigations done by students to show them what scientists do in real life. The project was aimed at secondary aged students, but Beare conducted research on a group of 15 , primary school teachers-in-training who had primarily studied only biology courses (therefore their knowledge level in astronomy was similar to that of a secondary student) to study the project while in its initial stages. The students took pictures and made measurements of galaxies using the telescopes and computer software throughout the course. The students were given a questionnaire and asked to give additional feedback for each question regarding their thoughts and experiences with the Faulkes Telescopes. Observations were also made of students during the project. Beare found that the students were very positive about the project; nearly all students agreed that the telescope was beneficial and the live images were important and impressive. "The adjectives used [by students] speak for themselves in regard to the ability of the real time observing to inspire enthusiasm and interest: amazing, fantastic, exciting, inspiring, fascinating, motivating. One student wrote 'This has been the most exciting thing I have done on this degree so far'" (Beare, 2007, p. 294). 
Beare theorized that as intended, the Faulkes Telescope Project would inspire students to want to learn more about astronomy.

These studies of interest show that it is important for students to be interested in what they are learning, whether through hands-on activities or real-life scientific investigations. Students were more interested in these types of activities than textbook units, and as a result, had more positive attitudes toward science. Interest should be a consideration in science curriculums.

\section{Understanding}

Fortus, Dershimer, Krajcik, Marx, and Mamlok-Naaman (2004) claimed that the goal of their Design Based Science (DBS) was to promote understanding and problemsolving skills through student projects that involved designing 2-D and 3-D models. DBS uses real-world contexts that are designed to not only be interesting but challenging as well. They designed three units to measure the amount of increase in knowledge and problem-solving skills through the use of real-world projects. These units were designed to be aligned with the National and Michigan's Department of Education Standards and Benchmarks for math and science, which encourage the use of real-world contexts to meet educational goals.

Fortus et al. believed that if students are to solve real-world problems, they need to learn new concepts related the problem. Each of the three units required students to design 2-D and/or 3-D models of various projects, such as a new cell phone design, in teams. They then presented and in some cases tested their models. The analysis for both low and high achieving students showed "that at the end of each unit the students had 
substantial science knowledge that they were able to apply to the solution of design problems" (Fortus et al., 2004, p. 1098).

Barab, Hay, Barnett, and Keating (2000) researched the effect of the use of virtual and scaled-down models designed and used by college students to help them to better understand Earth-Moon-Sun systems. The virtual models were "designed to engage students in constructing concrete artifacts and, in the process, develop rich understandings of astronomical phenomena" (p. 749). These researchers collected data for two years using observations, field notes, and pre- and post-interviews with students and instructors. Fifteen pre- and post-interviews were videotaped, they lasted around 30 minutes each. The students were asked probing questions where they explained and demonstrated their understanding of astronomical phenomenon using spheres and white boards. It was found that students had alternative conceptions during pre-interviews whereas the post interviews showed students understood and were able to correctly explain difficult astronomical phenomena. The students in the study also demonstrated the ability to use concepts from one situation and apply them in another, which shows that the students did gain a deep understanding of concepts.

Students understand what they have learned when they have the ability to apply, interpret, explain, and solve problems using new and previously known knowledge. "Rote learning is arbitrary, verbatim, and not related to experience with events or objects, and lacks affective commitment on the part of the learner to relate new and prior knowledge" (Chin and Brown, 2000, p. 109). "Meaningful learning... is learning that is tied to previous knowledge; students understand the material well enough to manipulate, paraphrase, and apply it to novel situations" (McGuire, 2006, p.8). An important aspect 
of understanding concepts is the ability to think and translate what has been learned to other problems and go beyond what the simple memorization of facts would require. Chin and Brown theorize that there are two different approaches to learning; the deep approach and the surface approach:

...the deep approach is associated with intrinsic motivation and interest in the content of the task, a focus on understanding the meaning of the learning material, and attempt to relate parts to each other, new ideas to previous knowledge, and concepts to everyday experiences. There is an internal emphasis where the learner personalizes the task, making it meaningful to his or her own experience and to the real world. In contrast, the surface approach is based on extrinsic or instrumental motivation. The learner who uses a surface approach perceives the task as a demand to be met, tends to memorize discrete facts, reproduces terms and procedures through rote learning, and views a particular task in isolation from other tasks and from real life as a whole. $(2000$, p. 110).

Chin and Brown conducted a study that compared deep and surface approaches to learning. They collected data through observations, student work, and pre- and postinstructional interviews of six (three boys and three girls) $8^{\text {th }}$ grade science students. The students were independently identified by their teacher and a Learning Approach Questionnaire that classified a boy and a girl for each of the following classifications: deep learner, between deep and rote learner, and rote learner. Chin and Brown analyzed the data and looked for patterns in behavior, thinking, and events. They found that students who used a deep approach "generated their ideas more spontaneously and their responses were more precise and elaborate.... [the students] referred to relevant daily life experiences to understand phenomenon" (2000, p. 130). Chin and Brown found the students who used a surface approach used explanations that reformulated the questions and used descriptions that only referred to what was visible and "referred to more basic and procedural information" (2000, p. 130). Chin and Brown suggest that teachers need 
to get students involved in asking questions, formulating explanations, and making predictions to promote a deep understanding of concepts and to help facilitate deep learning.

These studies on understanding showed that to promote understanding and to increase knowledge, real-world projects, as well as scaled-down or hands-on models, are beneficial. Student understanding is increased when they are given opportunities to apply, interpret, explain, and solve problems through the use of real-world contexts. Teachers are encouraged to use instruction that engages students and promotes understanding.

\section{Retention of Knowledge}

Increased retention and understanding of concepts might be possible through the use of real-world contexts. It is believed that if students are able to form/understand a relationship among concepts, their understanding will last longer than just memorizing a list of facts and formulas.

Lindemann-Matthies and Kamer (2005) studied the effect of interactive learning tools, such as touch-tables versus informative posters, on interest, knowledge, and retention for adult visitors to a Swiss Zoo. The participants were broken into two groups. Participants in the control group were able to receive information on zoo animals only through labels and posters placed outside of animal pens. The participants in the test group had access to the labels, posters, zoo rangers who answered questions, and touch tables, which had objects such as feathers, fur, food, bones, and other materials specific to each animal for visitors to touch. The touch table for the bearded vulture was 
specifically studied. Participants in the study were given a questionnaire to determine their level of interest, the amount they learned from various zoo exhibits, and subsequently how much information from the zoo exhibits was retained 2 months after their visit to the zoo. This research showed that more people answered questions about zoo animals correctly if they had used the touch-tables. They also found that 2 months after the zoo visit, $17 \%$ of zoo visitors using the touch-tables had sought further information and that the same number of correct answers were given by touch-table users in the follow-up questionnaire and the zoo exit questionnaire, both of which included questions regarding the level of knowledge zoo visitors had about specific zoo animals. Retaining the concepts gives the students a strong foundation to build on and is necessary to be efficient in learning new concepts and eventually to the workforce. Semb and Ellis (1994) describe school as a place for learning and that some of what is learned should be remembered. They go on to say that what has been learned is needed later for the real world, jobs, and further education. This need for remembering information led Semb and Ellis (1994) to study what and how much students remember. Semb and Ellis (1994) reviewed hundreds of studies of retention and narrowed them down to 56 articles based on the following criteria: 1 . The studies must be about knowledge retention; 2 . The study must be about academic content that is taught for 2 or more days; 3 . The study must have a one-week retention interval; 4 . The study must involve non-handicapped students at the junior high level or above; and 5. The study must use original data. Semb and Ellis found that "instructional strategies that actively involve students in learning may result in qualitatively different memories that are more resistant to forgetting than memories acquired through more traditional instructional methods" (p. 279). They found that 
students who were taught for mastery and using methods that promote higher levels of learning, had a chance to practice what was learned, and learned the content over a longer time period, had higher retention rates than students taught traditionally.

Nuthall (2000a, 2000b) studied the retention of knowledge by making observations and interviewing students, ages $9-12$ years old. Nuthall found that students need to interact with new concepts three to four times for the concept to become part of the long-term memory (Nuthall, 2000a). "When students engage with curriculumrelevant information during classroom activities, their minds construct a representation of that information in a long-term working memory" (Nuthall, 2000b, p. 289). Nuthall specifically described a student who had repeated interactions with the topic of rainfall in Antarctica; the student was able to correctly answer a test question regarding Antarctica's rainfall and could still remember the information correctly in an interview eight months later (Nuthall, 2000b). Nuthall determined that if new concepts were not connected to related information it would disappear from the students' working memory and that the amount of elapsed time was significant for the retention of the concepts.

These studies of retention showed that interactive learning improved retention of concepts. Retention is important for future learning, life outside of school, and future careers. Students need to master concepts through multiple interactions, to retain what they have learned. 
(This page is deliberately blank) 


\section{Chapter 3}

\section{Procedures}

I used a unit that involved studying, designing and building bridges as a way to incorporate real-world contexts in my physics classes. I modeled the unit after the information that I learned in ENG5100 The Engineering Process, at Michigan Technological University. The unit was taught for three consecutive years, one physics class per year, with class sizes ranging from 7 to 14 students.

I was fortunate enough to work in a school where I was encouraged to try new approaches in my teaching. My principal believed in allowing teachers to use their creativity to engage their students as long as the class requirements were met. Working in this teaching environment helped me to design my bridge unit and implement it with my students.

This bridge unit required only limited equipment and materials to teach. The use of the library computers was necessary for one of the activities. The remainder of the unit was completed with only basic materials such as glue, manila file folders, and a scale. It is a unit that is well suited for a school facing budget constraints.

\section{School Setting}

I taught at Atherton High School (Atherton), located in Burton, Michigan. Burton is a suburb of Flint, located in Genesee County. Genesee County is approximately 642 square miles with a population of 437,349 people as reported by the Michigan Economic Development Corporation (2007). There are three school districts in the City of Burton; each district has its own high school. Approximately 350 ninth through twelfth grade 
students attend Atherton. There are several factories in the area, which employ many people in the community. Many students planned to work in the factories upon graduation and, based on initial conversations with the students, did not recognize the value of science and mathematics. They perceived that knowledge in these subjects would not be required to obtain employment. Through implementation of the bridge unit, I hoped to spark interest in science and stimulate the students to recognize that opportunities beyond factory employment were available with additional education.

\section{Students}

The school was small enough for all of the students to know each other. Most students had attended school in the district since kindergarten. There were 34 physics students combined from 3 classes, 14 students from the class of 2003, 13 students from the class of 2004, and 7 students from the class of 2005. All of the physics students were seniors and all but one had completed at least Algebra 2 prior to taking physics.

Many of Atherton's students were from low-income families. According to the Center for Educational Performance and Information, at least $50 \%$ of the lunches served in Atherton's entire district were free or reduced during the school years of $2002-2003$, 2003 - 2004, and 2004 - 2005 (State of Michigan, 2007) (Table 1). Thirty-seven percent or more of Atherton's High School students received free or reduced lunches during the same time period (State of Michigan, 2007) (Table 1).

The graduation rate for Atherton for the class of 2003 was slightly below the state average of $84.8 \%$, while graduation rates in 2004 and 2005 were above the state average of $88.7 \%$ and $87.7 \%$ respectively (Table 2 ). The graduation rate for physics students was 
$100 \%$ during the school years of $2002-2003,2003-2004$, and $2004-2005$, which was above average as compared to the State of Michigan's and Atherton High School's rate.

\section{Table 1. Free and Reduced Lunch Statistics for Atherton High School}

\begin{tabular}{ccccc}
\hline & \multicolumn{2}{c}{ District } & \multicolumn{2}{c}{ High School } \\
\cline { 2 - 5 } School Year & Enrollment & \% Meals Served* & Enrollment & \% Meals Served* \\
\hline $2002-2003$ & 1014 & 50 & 337 & 37 \\
$2003-2004$ & 1057 & 51 & 346 & 42 \\
$2004-2005$ & 1063 & 57 & 365 & 42 \\
\hline *\% of Lunches that were free or reduced (Total Lunches Free + Total Lunches Reduced)/ Total Lunch Days
\end{tabular}

Table 2. Graduation Rates for State of Michigan and Atherton High School

\begin{tabular}{cccc}
\hline Year & State of Michigan (\%) & Atherton High School (\%) & Physics Students (\%) \\
\hline 2003 & 84.8 & 82.8 & 100 \\
2004 & 88.7 & 93.5 & 100 \\
2005 & 87.7 & 89.5 & 100 \\
\hline
\end{tabular}

The percent of students who pursued post-secondary education was $52 \%$ for the class of 2004 . The state average was $54 \%$. There were twelve students in the study and $83 \%$ pursued post secondary education, which is well above both the school and state average. Therefore these students did not fit the profile of a typical Atherton student. 


\section{Physics Teacher and Author of the Study}

I received a Bachelor of Science degree in applied physics with a minor in education in 1999, from Michigan Technological University (Michigan Tech). I taught for six years at Atherton and was the physics teacher, the head of the math department, and taught all of the upper level math courses, from fall of 2001 to the end of the school year in 2005. I taught six courses every day, one course during the planning period. The math courses that I taught during this time frame were general math, pre-algebra, algebra 2, pre-calculus, and calculus.

I had taught all of the physics students in one to two math classes prior to their senior year and therefore knew what each student's math abilities were upon entering the physics class. Almost all of the physics students were also enrolled in a math class that I taught while taking physics and therefore were in my classroom twice each day.

I was also the class of 2004 advisor at Atherton. As the class advisor, I was responsible for supervising and organizing student fundraising, class activities, and the prom put on by the students in 2003 .

\section{Curriculum Sequence}

Students who took physics generally took one of the following class sequences:

$9^{\text {th }}$ grade math/science: Algebra 1 or Geometry, and Earth science $10^{\text {th }}$ grade math/science: Geometry or Algebra 2, and Biology

$11^{\text {th }}$ grade math/science: Algebra 2 or Pre-Calculus, and Chemistry $12^{\text {th }}$ grade math/science: Pre-Calculus or Calculus, and Physics 
It was typical for students at Atherton High School to take six, 55-minute classes each day.

\section{Goals and Objectives}

The bridge unit that I designed was modeled after a portion of a course that I took at Michigan Tech as part of the Master of Science in Applied Science Education program. The bridge unit addressed sixteen Michigan Department of Education (MDE) Standards and Benchmarks (2003). A summary table of the MDE Standards and Benchmarks with the activities in the bridge unit that were designed to meet each goal can be found in Appendix A. Each activity will be described in detail in the Instruction section.

The bridge unit was not only designed to meet the specific MDE benchmarks, but to also increase students' interest in physics and to improve their understanding and retention of specific math and science concepts. The activities in the unit used real-world contexts and went beyond memorization activities. Students were expected to actively work in teams to design and build the best bridge.

\section{Bridge Unit Instruction}

The bridge unit was broken down into nine general activities. The activities served to introduce the unit, provide instruction on bridge types and force analysis, design and construct student bridges, test the bridges, and discuss what the students learned during the unit.

Activity 1. Project Presentation; time: 1 class period. This activity introduced the students to the bridge unit. Students were given the general goals and requirements of the 
unit. Students were informed of their role as the project manager and that they would be responsible for the completion of the project. Students were shown the bridge that I made in ENG5100 so they had a better idea of what they would be doing. The physics class was also informed that the chemistry class, along with other teachers and the principal, would help decide what bridge design to choose since they would take on the community role. These roles gave the students a better sense of a real bridge building project. Students were given the following scenario as the basis for the unit to help them feel connected to the work they were doing:

"A large river separates two communities; the people of both communities would like to be connected by a bridge. They cannot afford an expensive bridge, yet they want one that is aesthetically pleasing and safe. Both communities want to view scale models of the bridge design before choosing a contractor."

This activity was broken into four sections: 1 . Why are we doing this project?; 2 . Who would be involved in a real-life project of this type?; 3 . What role would each person play?; 4. An overview of the unit activities that will follow.

Why are we doing this project? This portion of the activity was a brief discussion to explain the goal of the project, which was to teach the students how to calculate forces in two dimensions and give them an understanding of how physics concepts are used in the real world.

Who would be involved in this type of project? Students were asked to brainstorm all of the professions that might be involved in a real-life project of this type. All ideas were listed on the board as well as professions that the students did not think of but might 
also be involved in the project. This portion of the activity gave students a sense of how many different professions are needed to carry out a project of this size.

What role would each profession play? This portion of the activity was a discussion with students regarding how each of the professions that had been listed in the previous section would be involved in building a bridge. Students stated what they knew about each profession and, as part of the discussion, learned more about each profession's role in the bridge building process. It was also a time for students to ask questions and construct the knowledge about the processes and professions involved in building bridges prior to the unit.

Overview of Unit Activities. The students were given a brief overview of the activities for the unit and were given a homework assignment to use the Internet to find different types of bridges. They were also required to name all of the bridges that they could think of and try to determine what type of bridge each was based on their research. The information that the students gathered was discussed during Activity 2.

Activity 2. Bridge types, terms, and examples; time: 2 class periods. Activity 2 was broken into two halves; in the first half students shared with the class the information they had gathered for the previous day's assignment. The bridge types and terms were all listed on the board. The students named all of the bridges they could think of and explained where they were located. They also tried to identify the type of bridge for each example listed.

As part of the first half of Activity 2, students were shown a slide show identifying each type of bridge. The different types were discussed in detail throughout 
the slide show. The slide show included pictures of the Mackinac, Cut River, Eagle River, Chevrolet Avenue, and Zilwaukee bridges, all of which are found in Michigan.

The slide show was designed to increase student interest. I believed that it would be much more exciting to look at actual bridges while learning about the various bridge types than it would be to simply lecture to the students about them. It is possible that the students gained a better understanding through the slide show because it gave them the opportunity to visualize the concepts being discussed. Their retention of this information was potentially increased through this type of activity as well.

The second portion of Activity 2 involved the discussion of forces on bridges (load) and types of deformation. The types of deformation were shown on the board and were demonstrated with a piece of foam. The students were also shown pictures and a short video of the Tacoma-Narrows Bridge collapse to see an extreme case of deformation.

Next, students determined what shapes were best for bridge stability. They were given Popsicle sticks as structural members and dough as an adhesive to create shapes in order to check their stability. This activity helped the students determine that a triangle is the most stable shape for designing a truss bridge. (A truss bridge is any bridge, which has 2 or more members, connected at joints making up the bridge's structure. Generally the members are under some type of force (load) causing them to be in either tension or compression.) It also helped students understand the importance of properly designing and building their own bridges and see the types of situations engineers and scientists face in real life. 
Activity 3. West Point Bridge Designer; time: 2 class periods. This activity required the use of the library computers. I started this activity by demonstrating the West Point Bridge Designer Software (The United States Military Academy at West Point, 2007) on the projector in the classroom. I showed the students some of the basic techniques of how to run the program and then took the class to the library to try the program for themselves.

The students first had to log on to http://bridgecontest.usma.edu/ to get the latest free version of the West Point Bridge Designer Software. The program allowed students to choose between several bridge types and sizes. Students were able to design their own bridge, decide what size and type of material to use for the bridge members, evaluate the cost to build the bridge, and even test the bridge under a load. The software showed a truck driving over the bridge; the members changed color to red or blue of varying intensities indicating members that are in tension or compression and to what degree. Varying shades (the lighter the color, the less force on the member) of blue and red indicated the amount of tension and compression, respectively, on each member. If the bridge was not designed properly, the bridge would collapse and the program would indicate to the students what members failed.

Activity 4. Bridge Member Analysis; time: 2 class periods. Activity 4 was broken into two parts: Analysis of forces on bridges by the Method of Joints and Method of Sections. The Method of Joints is used to calculate the forces on members of a truss bridge by calculating all forces present at each joint individually and in order from one side of the bridge to the other. The Method of Sections is used to calculate the forces on members of a bridge by looking at the forces present on a cross section of the bridge if it 
were cut at the desired location. Examples and practice worksheets for both of these analysis methods are provided in Appendix B. This activity was designed to teach students how to draw two-dimensional free-body diagrams, how to calculate forces on the members of the bridge through the Method of Joints and/or Sections, and how to determine whether a bridge member was in tension or compression (stretched or squeezed) due to forces acting on it.

The students began both methods by following these steps:

1. Label all joints and members. For example, label joints with A, B, C, etc., and label members with 1, 2, 3, etc.

2.Determine the amount of load on the bridge and to which joints it is being applied.

3.Decide which direction will be considered positive. For example, left, up, and counter-clockwise could be considered the positive directions.

4.Determine the length of all bridge members.

For Method of Joints, they continued as follows:

5. Draw free body diagrams including all forces for each joint.

6. Write out the sum of all forces for the $\mathrm{x}$ and $\mathrm{y}$ components.

7. Solve for unknown forces; positive force $=$ tension; negative force $=$ compression. Note the sum of forces in each direction should be equal to zero due to the fact that we do not want the bridge to move.

8. Continue in this manner for all joints.

For Method of Sections, the following steps were used: 
5. Assume the bridge was sliced to expose three members, each exerting an unknown force.

6. Draw a free body diagram, including all forces and a point not on the diagram to which the portion of bridge would rotate about if able.

7. Write out the sum of all forces (three equations for three unknowns). Note: that the equations for $\mathrm{x}, \mathrm{y}$, and rotational moments should again be set to zero, so the bridge is stationary.

8. Solve for all unknowns.

9. Continue solving for all member forces.

The students were given practice worksheets after working through several example problems in class. The students were free to ask questions throughout this activity to help enhance their understanding of the concepts.

Activity 5. Requirements for the Project; time: $1 / 3$ of a class period. The students worked in groups of two or three. Students were allowed to choose their own groups because they needed to do an extensive amount of work outside of class and needed to be able to easily arrange the time necessary to do their work. The groups were given the project requirements, rules, grading rubric, and hints to help the process along. (Appendix C). Students had the opportunity to ask questions regarding the project and had access to all necessary design and building materials at that time.

Following the discussion of all the bridge requirements, the students were able to break into their groups and begin working on designing their bridge and working out the force calculations. They were encouraged to ask questions at any time. 
Activity 6. Bridge Design; time: 1 2/3 class periods. Students continued working on their bridge designs and calculations in class, in addition to outside of class. The calculations done on their own bridge designs gave the students extra practice with twodimensional force calculations.

Activity 7. Bridge Construction; time: 3 class periods. This activity required the students to build the bridges they had designed. The materials used for this process were manila file folders and white glue, along with the necessary instruments used to cut and measure the file folders. The students were required use their calculations to determine the size and type of members to build (compression or tension). The bridge members had to be constructed carefully and connected at the proper angles. The students had the opportunity to learn that the best bridge design would not work if the bridge was poorly constructed in this portion of the unit. This was also an opportunity for students to see that there was more to science, technology, and math than just making calculations; they also had to ensure that their designs were built according to their calculations.

Activity 8. Bridge Competition; time: 1 class period. This portion of the unit was where the bridges were load tested and judged. The students brought their bridges to class as soon as they got to school in the morning. Each bridge was assigned a number so that the "community members" (Chemistry class, other teachers, the principal, etc.) could judge the aesthetics of each bridge without knowing the identity of its creators. "Community members" were given observer surveys where they rated each bridge for creativity, neatness, and whether or not they thought it would be safe. (Appendix: D) The dimensions and mass of each bridge were measured during class. After judging and determining the mass of the bridges, students set up their bridges between two desktops 
for load testing. The bridges were required to hold 4 kilograms (students were required to calculate the load on the bridge with the given mass), in the form of textbooks centered on the top of the bridge, for at least one minute. All of the information regarding each bridge's performance, dimensions, and mass was collected and recorded. The bridge grading rubric used the above information to determine a portion of the students' grade for the unit. (Appendix D).

Activity 9. Post-Competition Discussion; time: 1 class period. This activity was designed to help reinforce everything the students learned throughout the unit and address any questions they may still have had. The students also were given a chance to talk about what they might do differently and what they liked most about the unit. I gave the students a student survey (Appendix D) regarding their thoughts about the unit at this time as well. The feedback form also gathered information about the students' interest in the unit. The remaining class time was used to prepare for the unit test and for working on the laboratory write-ups.

\section{Procedures}

A timeline for the events of this study is given in Table 3. The students were given a pretest after finishing the previous chapter's test. The pretest was followed by about 14 class periods of instruction, project work, and a bridge competition. The students were then given a posttest. The students were taught a traditional unit on Universal Gravitation following the bridge unit that lasted approximately 11 class periods. The traditional unit was followed by a traditional test. Twelve of the students participated in a post-graduation questionnaire that was given in December 2006. 
Attempts were made to contact all 34 students from the three physics classes, however only 12 students were located and completed the post-graduation questionnaire.

Pretest. Prior to the start of this bridge unit, students were expected to know: 1) basic trigonometry concepts - sine, cosine, and tangent; 2) how to solve systems of equations (from the previous math class, Algebra 2 and/or Pre-calculus); and 3) how to calculate force using the equation $\mathrm{F}=\mathrm{ma}$ (from the previous physics chapter on onedimensional forces).

\section{Table 3. Timeline of events}

\begin{tabular}{lll}
\hline \multicolumn{1}{c}{ Year } & \multicolumn{1}{c}{ Date } & \multicolumn{1}{c}{ Activity } \\
\hline $2002-2003 *$ & Dec. 20 & Pretest \\
& Dec. $21-$ Jan. 5 & Christmas Break \\
& Jan. 6 & Bridge Unit Instruction Begins \\
& Jan. 23 & End of Instruction \\
& Jan. 24 & Posttest \\
& Jan. 27 & Traditional Unit Instruction Begins \\
& Feb. 10 & End of Instruction \\
\hline * The 2003-2004 class and the 2004-2005 class followed the same general timeline for class activities.
\end{tabular}


Students were given a pretest with five questions requiring a total of twelve answers (Appendix E) to assess their prior knowledge of the concepts to be taught throughout the bridge unit. Students received extra credit for completing all of the questions even if they were not correct. The answers given were later compared with their posttest answers. (Appendix F). This pretest also provided an early indication of any areas of the new unit that would need extra emphasis.

Embedded Assessment. The students were assessed throughout the unit using a variety of methods, including assignments and observations I made during class discussions and activities; however, only my recollections of observations will be used for the purpose of this study. Observations of students were used to determine the level of interest due to the real-world contexts of the bridge unit.

Posttest. The students were given a posttest (Appendix B) following the conclusion of the unit. This test contained five questions that were the same as or similar to the pretest so that the change in understanding could be determined. The posttest also included an additional five questions directly corresponding to activities and concepts from the unit. These additional posttest questions required comprehension and interpretation of data to correctly answer them.

Any time remaining after the students finished their posttest was used to work on the lab write-ups. The lab write-ups, which required the students to document what they had learned and their experiences throughout the unit, were due the day following the posttest.

Traditional Unit Instruction and Test. The traditional unit was a unit on Universal Gravitation. This traditional unit was taught after the bridge unit, as a 
traditional textbook based unit from the Merrill Physics: Principles and Problems textbook (Zitzewitz \& Neff, 1995). The unit lasted approximately 11 class periods and was followed by a traditional test.

The students were instructed on Kepler's Laws, the Law of Universal Gravitation, orbital motion, freefall, gravitational fields, and black holes. Instruction included two small labs on freefall and a lab on elliptical orbits used to demonstrate force variations. The students also did practice problems throughout the unit and a chapter review before the unit test. Example problems and the test are in Appendix G.

Post-Graduation Questionnaire. A post-graduation questionnaire (Appendix H) was given to ascertain the students' thoughts about the unit after they had left high school and how much they had retained from doing the unit. It also evaluated what career/educational paths students had followed, their current status (student, full time job, etc), their future plans, and how they felt math and science classes and this particular unit had influenced their ideas regarding math and science. The questionnaire did not ask students to refrain from looking at notes they may have kept from class.

Two students were contacted, in the beginning of December 2006, to get contact information for other physics students from the classes of 2003, 2004, and 2005. These two students were able to give contact information for eleven other students. These eleven students were contacted and through them, four additional student's contact information was found.

The post-graduation questionnaire was emailed to the 17 students, who were located, from these three classes. The students began returning the questionnaires in January 2007. I emailed the students several times, as well as had the students email each 
other, in an attempt to get as many students as possible to respond to the questionnaire. Twelve of the 17 students responded to the questionnaire, I received the last questionnaire back at the end of April 2007. Depending on the date of graduation, the

students had not participated in the unit for up to 4 years (Table 4 ). The number of years that the students were out of school may have affected their questionnaire results, however, a student who took the course in 2003 had one of the highest scores.

\section{Analysis}

Data was collected from the pretest, posttest, and post-unit questionnaire. All rubrics are given in the Appendix with the corresponding assessment; for example, the rubric for the pretest is in Appendix E, along with the pretest and answer key and so on. The data from these instruments was used to determine the level of student understanding and the amount of retention for the concepts in the unit. The posttest scores were also compared to the scores on a test taught through traditional methods using comparisons made of the mean, median, range and standard deviation for both tests of all 34 students, to further assess levels of student understanding. 
(This page deliberately blank) 


\section{Chapter 4}

\section{Results}

There were three physics classes involved in the study - the class of 2003 with 14 students, the class of 2004 with 13 students, and the class of 2005 with 7 students - for a total of 34 students. Attempts were made to contact all 34 students beginning in December 2006 in order to administer the post-graduation questionnaire (Appendix H). Seventeen students were not located and five other students were located but never completed the post-graduation questionnaire. Twelve of the thirty-four students, or $35 \%$, did complete the post-graduation questionnaire (class of 2003: 2 female and 2 male students; class of 2004: 3 female and 4 male students; class of 2005: 1 male student) (Table 4).

\section{Post-Graduation Questionnaire Sample}

The median of the posttest scores for the sample of twelve students who took the post-graduation questionnaire was $79 \%$, with a range of $29 \%$, mean of $81 \%$, and standard deviation of 5\% (Table 5). The median for these students was not remarkably different than the overall class median (class meaning all 3 physics classes combined, 34 students) for the posttest, which was $78 \%$, with a range of $38 \%$, mean of $80 \%$, and standard deviation of $9 \%$ (a table of scores for the 34 students is in Appendix I). The percentage of females and males for the twelve students was $42 \%$ and $58 \%$, respectively. The percentage of females and males in the overall class was $44 \%$ and $56 \%$, respectively. 
Therefore, it is reasonable to conclude that the twelve students who completed the postgraduation questionnaire form a good representation of all students in the three classes.

Only the scores and comments from the twelve students who completed the postgraduation questionnaire will be used to discuss the results for interest and retention of this bridge unit. The results for understanding will compare all 34 students on the pretest, posttest, and traditional test. My recollections of observations made during class include all 34 students. Pseudonyms were used in place of the students' actual names.

Table 4. Distribution of Students from Post-Graduation Questionnaire

\begin{tabular}{cccc}
\hline Student & Male/Female & Graduation Year & $\begin{array}{c}\text { \# Years Out of } \\
\text { School }\end{array}$ \\
\hline Jill & F & 2003 & 4 \\
Kim & F & 2003 & 4 \\
Ken & M & 2003 & 4 \\
Tom & M & 2003 & 4 \\
Ann & F & 2004 & 3 \\
Beth & F & 2004 & 3 \\
Sue & F & 2004 & 3 \\
Don & M & 2004 & 3 \\
Mark & M & 2004 & 3 \\
Matt & M & 2004 & 3 \\
Sam & M & 2004 & 3 \\
Ben & M & 2005 & 2 \\
\hline
\end{tabular}




\section{Table 5. Twelve Student and Overall Class Statistics.}

\begin{tabular}{lcc}
\hline & Twelve Students (\%) & All Classes (\%) \\
\hline Median of Bridge Unit Posttest & 79 & 78 \\
Range of Bridge Unit Posttest & 29 & 38 \\
Mean of Bridge Unit Posttest & 81 & 80 \\
Standard Deviation & 5 & 9 \\
Gender Statistics Female & 42 & 44 \\
Gender Statistics Male & 58 & 56 \\
\hline
\end{tabular}

\section{Interest Results}

I had two sources of information for determining the level of student interest: written student comments from the post-graduation questionnaire and my unwritten recollections of student participation in the activities. These observations were not recorded because I had not decided to do the study until after the classes were completed.

Post-Graduation Questionnaire. The post-graduation questionnaire (Appendix H) asked 4 questions, question numbers 16 (Table 6), 17 (Table 7), 20 (Table 8), and 21 (Table 9), to determine student interest in the unit and in the physics class. The responses to these questions, in general, showed interest in the unit and class. Question 16 asked students what their favorite part of physics class was; 4 out of 12 students stated that the bridges were their favorite part. Question 17 asked students what their least favorite part of physics class was; no students stated that the bridge unit was their least favorite part. Question 21 asked students whether or not they thought the bridge unit made physics 
more interesting. All twelve students indicated that they thought that the bridge unit did make physics more interesting. Two students mentioned that they "liked the calculations and seeing how it would come together" and "seeing we could build a bridge with just some equations".

Anecdotal Observations of Twelve Students. The recollections I have of the twelve students who took the post-graduation questionnaire indicated that they were interested in the bridge unit. I recall that two groups from the class of 2004, which included Ann, Beth, and Laura (who did not complete the survey), and Matt and Sam, seemed to enjoy competing with each other in designing and building their bridges. All four of these students mentioned that their bridge was the "best" or that it "won" the competition in the questionnaire. I also recall Kim, from the class of 2003, commenting one day in class that she saw bridges everywhere she went. She mentioned that she found herself watching car commercials and where she paid more attention to the bridges the cars were on than the cars themselves.

The students always displayed a high level of interest in the bridge unit as evidenced by both their discussions and behavior during class. They did not complain or show signs of indifference at any time during the bridge unit, which I had seen sometimes during other traditionally taught units. It is my belief that my observations of student interest in the unit were consistent with the students' responses to the post-graduation questionnaire. 


\section{Table 6. Question 16, What was your favorite part of physics class? Why?}

\begin{tabular}{|c|c|}
\hline Student & Response \\
\hline Jill & The bridge competition was fun \\
\hline Kim & The bridges \\
\hline Ken & I liked when we did labs, it made class more interesting \\
\hline Tom & When we went to the creek and "Adam" got a leech \\
\hline Ann & $\begin{array}{l}\text { I like building the bridges. It was a lot of work and calculations but I think } \\
\text { that it was fun and we got to work in groups }\end{array}$ \\
\hline Beth & $\begin{array}{l}\text { The Cedar Point trip, because that was a blast., and building the bridge } \\
\text { because my group won. }\end{array}$ \\
\hline Sue & Formulas, they are very systematic \\
\hline Don & $\begin{array}{l}\text { My classmates and the class atmosphere. We always had a good time in class } \\
\text { and enjoyed it. }\end{array}$ \\
\hline Mark & $\begin{array}{l}\text { Frankly, I enjoyed physics the most because it gave me the opportunity to be } \\
\text { with fellow seniors that I knew I may rarely talk to ever again. }\end{array}$ \\
\hline Matt & Problem solving \\
\hline Sam & $\begin{array}{l}\text { Doing problems that were related to when I wrecked my car, it was neat to } \\
\text { see how physics could be related to anything }\end{array}$ \\
\hline Ben & I liked the bridges, it was fun creating something instead of doing problems \\
\hline
\end{tabular}


Table 7. Question 17, What was your least favorite part of physics class?

Why?

Student Response

Jill I hated when we had to read the book

Kim The math behind it makes physics much easier. I wish we could have used calculus in the class.

Ken Homework

Tom The homework, I knew it was important but I hated doing it.

Ann I didn't like calculating things at all. Like velocity and all of those book problems.

Beth Nothing really honestly

Sue Exams, testing on a vast amount of material and based on a great deal of memorization of formulas

Don Tests, I always thought I had a grasp on information but come test time I would forget stuff

Mark I disliked physics only in that it offered math questions I was not familiar with, and thus unprepared to answer quickly. The difficulty proved not only to be a burden, but it was what made the class worth taking.

Matt None

Sam The homework

Ben When I missed class, it was hard to catch up 


\section{Table 8. Question 20, What was your favorite/least favorite part of building the bridges? Why?}

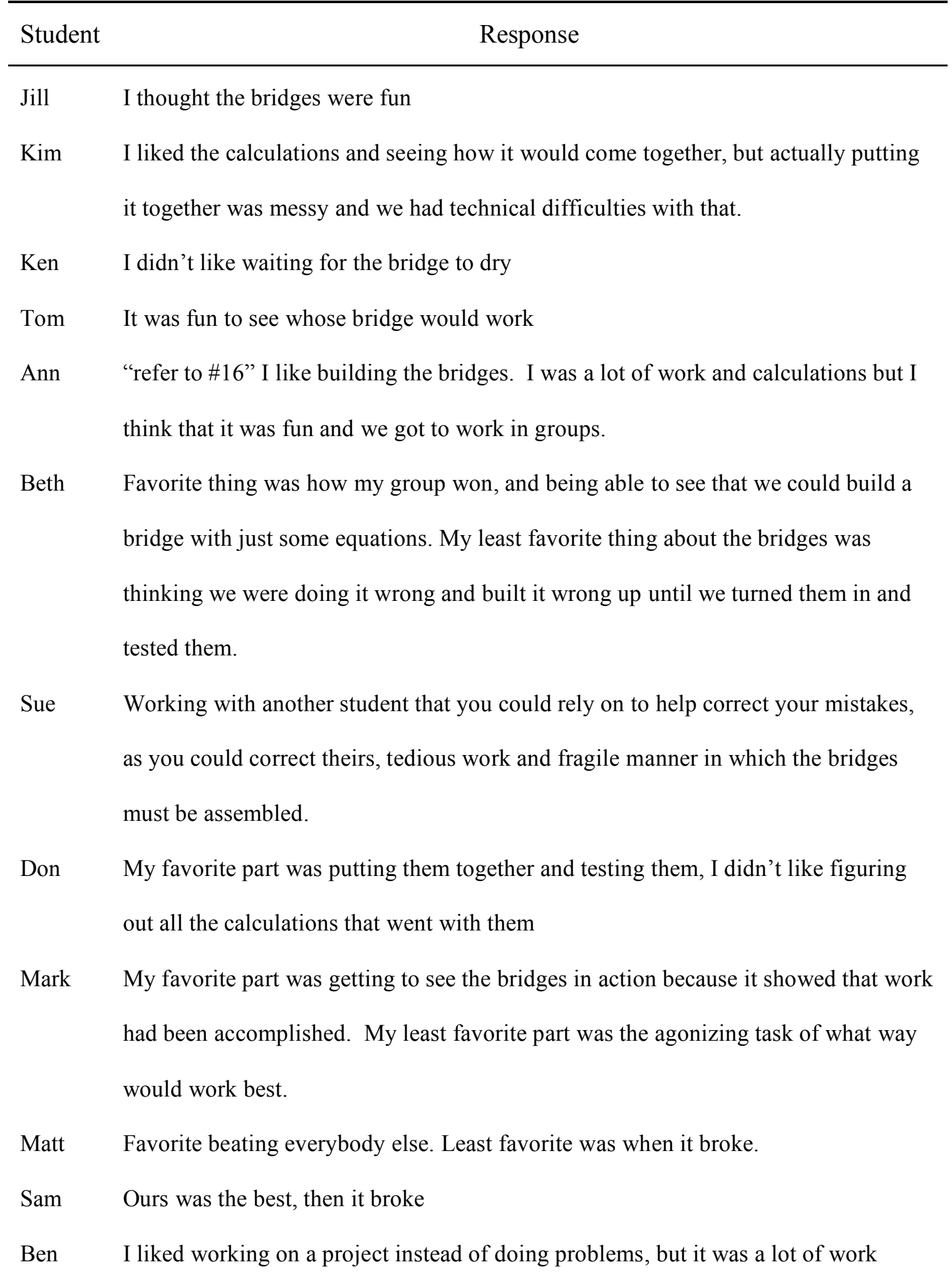


Table 9. Question 21, Did doing the bridge project make physics more or less interesting? How?

\begin{tabular}{ll}
\hline Student & Response \\
\hline
\end{tabular}

Jill The bridges were definitely more interesting

Kim Yes. It showed how physics can be applied in real life. Although with 10 calculus based college credits, I haven't done anything like that again.

Ken Any time we did a project made class more interesting, I liked the bridges

Tom It was more interesting when we worked on the bridges

Ann It made it way more interesting especially when we made it a contest and me "Beth" and "Laura" beat "Matt" and "Sam"!!!

Beth Very more interesting. It was very interactive.

Sue More, got to see how formulas could work in a real life situation

Don More

Mark It made physics more interesting because it put us solely in charge of a physics application.

Matt More interesting because I was able to use my hands and apply what I've learned to build something that I can visually see.

Sam Definitely more interesting, I like to do projects

Ben It was more interesting, I liked building something and working with someone else 
Other General Comments for all 34 Students. My recollections of all three physics classes during the bridge unit were that the students seemed more interested during the bridge unit than during other traditional units. They asked many questions during the bridge slide show and often commented on which bridges they liked. The students also seemed to be interested in the West Point Bridge Designer Software (WPBDS). I recall that some of the students competed to see who could design the best bridge, by seeing who could design a bridge that would hardly change color as the truck (load) crossed. They also competed to see who could design the worst bridge during the class time while they worked with the WPBDS program. They tried to determine the minimal requirement for the bridge to hold the truck (load), what would cause the bridge to collapse while the truck crossed, and what design would make the bridge collapse before the truck even got on the bridge. The rest of the students in the class simply practiced using the program without competing with anyone else. These instances were observed while students worked with the program in class.

It seemed, from observations I made of my students during class, that all of my students were really proud of their hard work and the resulting bridges. I estimate that twenty percent of the student groups gave their bridges names (such as a combination of their first or last names; one group used a made up name from a popular movie that was in the theaters) and/or decorated them with markers. Mark, class of 2004, a student who completed the post-graduation questionnaire pointed out that "getting to see the bridges in action - it showed that work had been accomplished". 


\section{Understanding Results}

Pretest Versus Posttest. All students $(\mathrm{N}=34)$ were given a pretest before the bridge unit began. The students' pretest scores were compared to their scores on the posttest for the bridge unit to determine whether or not the students learned the concepts taught in the unit. Every student had a higher score on the posttest than on the pretest (Appendix I). The median score on the pretest for the 34 students was $8 \%$, with a range of $33 \%$, mean of $11 \%$, and standard deviation of $7 \%$. Ten of the students received scores of zero on the pretest. The median score for the posttest for all 34 students was $78 \%$, with a range of $38 \%$, mean of $80 \%$, and standard deviation of $9 \%$. All of the students had scores of $62 \%$ or higher on the posttest.

A comparison of the twelve students who took the post-graduation questionnaire is in Table 10. All twelve students who took the post-graduation questionnaire had higher scores on their posttest than they did on the pretest (Table 10). The median score for the pretest was $17 \%$, with a range of $33 \%$, a mean of $13 \%$, and a standard deviation of $7 \%$. Three of the students received scores of zero on the pretest. The median score on the posttest for these twelve students was $79 \%$, with a range $29 \%$, a mean of $81 \%$, and a standard deviation of $5 \%$. All twelve students had scores of $70 \%$ or higher on the posttest.

Posttest versus Traditional Unit Test. Two units were compared to determine if the students learned the information better when they were taught using a real-world context or using a traditional textbook/lecture method of teaching. The first unit was the bridge unit, which was designed around a real-world situation and had many hands-on 
activities. This unit was compared to a unit on Universal Gravitation, which was taught as a traditional textbook based unit from the Merrill Physics: Principles and Problems textbook (Zitzewitz \& Neff, 1995), this unit will be referred to as the traditional unit.

Table 10. Pretest versus Posttest*

\begin{tabular}{|c|c|c|}
\hline Student & Pretest $\%$ Correct & Posttest \% Correct \\
\hline Jill & 0 & 72 \\
\hline Kim & 33 & 99 \\
\hline Ken & 25 & 88 \\
\hline Tom & 17 & 83 \\
\hline Ann & 8 & 81 \\
\hline Beth & 0 & 76 \\
\hline Sue & 17 & 76 \\
\hline Don & 17 & 70 \\
\hline Mark & 17 & 84 \\
\hline Matt & 17 & 94 \\
\hline Sam & 8 & 72 \\
\hline Ben & 0 & 72 \\
\hline Median & 17 & 79 \\
\hline Range & 33 & 29 \\
\hline Mean & 13 & 81 \\
\hline Std. Dev. & 7 & 5 \\
\hline
\end{tabular}

* The pretest was out of 12 points; the posttest was out of 60 points 
Seventy-nine percent of the students $(\mathrm{N}=34)$ had higher test scores on the bridge unit posttest than on the traditional textbook unit test (Appendix I). The median score for these students on the bridge posttest was $78 \%$ (mean $=80 \%$, range $=38$, standard deviation $=9$ ), whereas the mean score on the traditional unit test was $73 \%$ (mean $=73 \%$, range $=45$, standard deviation $=11$.

Seventy-five percent of the twelve students who took the post-graduation questionnaire followed the trend of the rest of the class and had higher test scores on the posttest than they did on the traditional unit test (Table 11). The median and mean were higher for the bridge unit posttest than they were on the traditional test; the median and mean were $78 \%$ and $80 \%$, respectively, for the bridge posttest while the traditional unit median and mean were both $73 \%$.

Student Responses Regarding Understanding. The post-graduation questionnaire was given to the previously mentioned twelve students to determine their thoughts about whether or not real-world examples and applications increased their interest and/or their understanding of physics concepts. Question 22 (Table 14) asked students to describe whether or not they thought that learning through projects made the concepts easier to understand. Ten of the twelve students said that they felt that it was easier for them to understand concepts taught through projects or real-world applications. Some sample student comments from the questionnaire were "I got a better understanding of some of the calculations", "it gives students a chance to get out of their desks and put what they've learned in action", and "I believe projects can be beneficial by showing real world applications of abstract calculations". 
Table 11. Bridge Unit Posttest and Traditional Unit Test Data

\begin{tabular}{|c|c|c|c|}
\hline Student & $\begin{array}{l}\text { Bridge Unit } \\
\text { Posttest (\%) }\end{array}$ & $\begin{array}{l}\text { Traditional Unit } \\
\text { Test }(\%)\end{array}$ & Difference $(\%)$ \\
\hline Jill & 72 & 50 & 22 \\
\hline Kim & 99 & 73 & 26 \\
\hline Ken & 88 & 80 & 8 \\
\hline Tom & 83 & 70 & 13 \\
\hline Ann & 81 & 77 & 4 \\
\hline Beth & 76 & 74 & 2 \\
\hline Sue & 76 & 83 & -7 \\
\hline Don & 70 & 67 & 3 \\
\hline Mark & 84 & 91 & -7 \\
\hline Matt & 94 & 65 & 29 \\
\hline Sam & 72 & 75 & -3 \\
\hline Ben & 72 & 65 & 7 \\
\hline Median & 79 & 74 & \\
\hline Range & 29 & 41 & \\
\hline Mean & 81 & 73 & \\
\hline Std. Dev. & 5 & 10 & \\
\hline
\end{tabular}




\section{Retention of Knowledge Results}

Pretest Versus Post-Graduation Questionnaire. Results on the pretest and post-graduation questionnaire were compared to make a determination of learning because they were the most similar in design. Questions 23, 24, 25, 26, and 27 on the post-graduation questionnaire (Appendix $\mathrm{H}$ ) were similar to those on the pretest (Appendix E) that students were given prior to the start of the bridge unit. Both of these assessments, in general, asked for the same information, but the questionnaire had 3 fewer points possible (the pretest had one question that requested an additional response not requested on the questionnaire, the pretest also had a question that was completely different and was worth more points). Questions 24 and 25 requested students to give at least 3 examples to completely answer the question with each example counted as one answer and listed in the table below as $24 \mathrm{a}, 24 \mathrm{~b}$, and so on.

The student answers to questions, 23 through 27 were scored according to the rubric (Appendix H). The students were given one point for each correct answer on both the pretest and the post-graduation questionnaire. The results (Table 12) were compared to the results of the pretest (Table 13), to determine how many of the bridge unit concepts the students had retained. The students were expected to have scores no lower than they did before they started the bridge unit.

The median for the pretest for the twelve students was $17 \%$ and had a range of $33 \%$. The median score for the corresponding questions on the post-graduation questionnaire was $56 \%$ and had a range of $67 \%$. $100 \%$ of the students were able to answer at least 2 of the questions correctly on the post-graduation questionnaire. All 
twelve students had higher scores on the post-graduation questionnaire about the bridge unit than they received on the pre-unit test.

Table 12. Results of Post-graduation Questionnaire*

\begin{tabular}{|c|c|c|c|c|c|c|c|c|c|c|}
\hline \multirow[b]{2}{*}{ Student } & \multicolumn{9}{|c|}{ Question Number } & \multirow[b]{2}{*}{ Total \# correct } \\
\hline & 23 & $24 a$ & $24 b$ & $24 c$ & $25 \mathrm{a}$ & $25 b$ & $25 \mathrm{c}$ & 26 & 27 & \\
\hline Jill & 0 & 1 & 0 & 0 & 1 & 0 & 0 & 0 & 0 & 2 \\
\hline Kim & 1 & 1 & 1 & 0 & 1 & 1 & 0 & 0 & 0 & 5 \\
\hline Ken & 1 & 1 & 1 & 0 & 1 & 1 & 1 & 1 & 1 & 8 \\
\hline Tom & 1 & 1 & 0 & 0 & 1 & 1 & 0 & 1 & 1 & 6 \\
\hline Ann & 1 & 1 & 0 & 0 & 0 & 0 & 0 & 0 & 0 & 2 \\
\hline Beth & 0 & 1 & 0 & 0 & 1 & 1 & 1 & 0 & 0 & 4 \\
\hline Sue & 1 & 1 & 1 & 0 & 1 & 1 & 0 & 1 & 0 & 6 \\
\hline Don & 1 & 1 & 1 & 0 & 1 & 1 & 1 & 0 & 1 & 7 \\
\hline Mark & 1 & 1 & 1 & 1 & 1 & 1 & 1 & 0 & 1 & 8 \\
\hline Matt & 1 & 1 & 0 & 0 & 1 & 1 & 0 & 0 & 0 & 4 \\
\hline Sam & 1 & 1 & 0 & 0 & 1 & 0 & 0 & 0 & 1 & 4 \\
\hline Ben & 1 & 1 & 1 & 0 & 1 & 0 & 0 & 0 & 1 & 5 \\
\hline Median & & & & & & & & & & 5 \\
\hline Range & & & & & & & & & & 6 \\
\hline
\end{tabular}




\section{Table 13. Pretest and Post-graduation Questionnaire Data*}

\begin{tabular}{|c|c|c|}
\hline Student & Pretest $(\%)$ & Post-grad. Questionnaire (\%) \\
\hline Jill & 0 & 22 \\
\hline Kim & 33 & 56 \\
\hline Ken & 25 & 89 \\
\hline Tom & 17 & 67 \\
\hline Ann & 8 & 22 \\
\hline Beth & 0 & 44 \\
\hline Sue & 17 & 67 \\
\hline Don & 17 & 78 \\
\hline Mark & 17 & 89 \\
\hline Matt & 17 & 89 \\
\hline Sam & 8 & 44 \\
\hline Ben & 0 & 56 \\
\hline Median & 17 & 56 \\
\hline Range & 33 & 67 \\
\hline Mean & 13 & 60 \\
\hline Std. Dev. & 7 & 23 \\
\hline
\end{tabular}

*These are the number correct (for pretest out of 12 and questionnaire out of 9) 
Table 14. Question 22, Do you think that learning physics (or any class)

through projects makes it easier to understand? Why or why not?

\begin{tabular}{ll} 
Student & Response \\
\hline
\end{tabular}

Jill It is definitely easier to understand things taught through projects

Kim I think it gives relevance, but I don't think it makes the math easier.

Ken I think projects are easier to understand because they make the work fun

Tom A project always makes understanding something easier.

Ann It depends on the person. Some need hands on experience, some do not.

Beth Yes, a whole lot easier. I am a very hands on learner

Sue Yes, it gives students a chance to get out of their desks and put what they have learned into action

Don Yes I got a better understanding of some of the calculations

Mark I believe projects can be beneficial by showing real world applications of abstract calculations. However, if one does not understand the calculations before undertaking a real life project they will not be able to appreciate the project for its academic value.

Matt It could make the class easier to understand because it creates more interest for the students

Sam It's easier to do projects.

Ben Definitely easier to understand projects 
(This page deliberately blank.) 


\section{Chapter 5}

\section{Discussion and Conclusions}

\section{Discussion}

Interest. Observations of students during class activities (Chapter 3) led me to believe that the majority of students were interested in the bridge unit, which used realworld contexts to stimulate interest. Data collected through the post-graduation questionnaire indicated also that the students who responded to the questionnaire were very interested in the bridge unit. The design of this type of unit allowed the students to interact with each other and they became more involved with the concepts that they were learning rather than just taking notes or reading the textbook.

My observations and questionnaire results showed that the students were more excited during the bridge unit that incorporated real world concepts that the students could relate to, than during other traditional units. When the students were asked on the post-graduation questionnaire what was their favorite part of physics class, 4 of the 12 students stated that the bridge unit was their favorite. When asked specifically whether or not the bridge unit made physics class more interesting, $100 \%$ of the students stated that they felt the bridge unit made physics more interesting.

Understanding. All 34 students demonstrated higher degree of understanding upon completion of the bridge unit, as assessed through comparing the posttest to the pretest data. The students had very little knowledge regarding the questions on the pretest as their scores indicated, $29 \%$ were unable to answer any questions correctly. The students' scores on the posttest showed that they understood the concepts after completing the unit. They had a median score of $78 \%$ with a range of $38 \%$, mean of 
$80 \%$, and standard deviation of $9 \%$ on the posttest and remarkably, the lowest score was $62 \%$.

When the bridge unit posttest scores for all 34 students were compared to scores for the same students on the traditionally taught textbook unit on Universal Gravitation, it was found that $79 \%$ of the students had higher scores on the bridge unit. The bridge unit posttest had a median of $78 \%$, range of $38 \%$, mean of $80 \%$, and standard deviation of $9 \%$, while the traditional unit had a median of $73 \%$, range of $45 \%$, mean of $73 \%$, and standard deviation of $11 \%$. Although these two units did not focus on the same content, nor were these assessments similar in design, the higher test scores on the bridge unit posttest versus the traditional unit test led me to believe that these students understood the concepts that were presented in the bridge unit better than they understood the concepts taught through traditional methods.

Information that was gathered from the post-graduation questionnaire showed that real-world contexts improved understanding. Nine of the 12 students who completed the post-graduation questionnaire stated that they felt that incorporating real-world contexts made the concepts in the bridge unit easier to understand. Some of the students also felt that a real-world context facilitated learning in science and mathematics in general.

Retention. Of the students who responded to the post-graduation questionnaire, $100 \%$ were able to answer at least two questions correctly. I believe that this is an important difference because of these same twelve students; three were unable to answer any of these questions correctly on the pretest for the bridge unit. Therefore, not only had they gained an understanding of the concepts, they also remembered these concepts for up to four years after the concepts had been initially taught. It must be noted that these 
students could have encountered these bridge concepts in post-secondary courses, although I do not believe this to be the case and the questionnaire did not ask students to calculate forces. All but two students reported that they were pursuing fields of study or careers that are unrelated to engineering. The post-graduation questionnaire did not include questions regarding whether or not students retained other concepts taught through traditional methods; however, I do believe that the real-world contexts aided in the students retention of the bridge unit concepts.

\section{Conclusion}

This study showed that the use of real-world contexts improved student interest, understanding, and knowledge retention, and reveals the need to incorporate more realworld contexts into science and math courses. The interest that my students showed throughout and after the implementation of the bridge unit was directly related to the use of real-world contexts. I believe that all students would benefit from this type of handson approach. Students are able to see the reasons behind the concepts they are learning and become more interested in the concepts; therefore, they take a more active role in what they are learning. It is my belief that when students are interested in what they are learning, feel that the concepts have relevance to their lives, and can see where the concepts are used in the real world, they understand the concepts better and remember them longer.

Further Research. There are several related questions about the use of realworld contexts that should be researched in future studies. The first is related to how students' career paths after graduation are affected by the science curriculum that is 
studied by the students throughout their primary, middle, and secondary school careers. I would also be interested in studying the effect of implementing real-world contexts in science courses for primary and middle school students to see whether real-world contexts in science at early ages increase the number of students taking science in high school and college. One final topic that I am interested in studying is what amount of real-world context is needed to increase student understanding; is incorporating small portions or activities in a unit enough or is it necessary to have the entire unit comprised of real-world contexts? 


\section{References}

Barab, S. A., Hay, K. E., Barnett, M., \& Keating, T. (2000). Virtual solar system project: Building understanding through model building. Journal of Research in Science Teaching, $37.719-756$.

Bouillion, L. M., \& Gomez, L. M. (2001). Connecting school and community with science learning: Real-world problems and school-community partnerships as contextual scaffolds. Journal of Research in Science Teaching, 38, 878 - 898.

Bybee, R. W., \& Fuchs, B. (2006). Preparing the $21^{\text {st }}$ century workforce: A new reform in science and technology education. Journal of Research in Science Teaching, 43. $349-352$.

Beare, R. (2007). Investigation into the potential of investigative projects involving powerful robotic telescopes. International Journal of Science Education, 29, 279 $-306$.

Chin, C., \& Brown, D. E. (2000). Learning science: A comparison of deep and surface approaches. Journal of Research in Science Teaching,37. 109 - 138.

Christidou, V. (2006). Greek students' science-related interests and experiences: Gender differences and correlations. International Journal of Science Education, 28, 1181 $-1199$.

Fortus, D., Dershimer, R. C., Krajcik, J., Marx, R. W., \& Mamlok-Naaman, R. (2004). Design-based science and student learning. Journal of Research in Science Teaching, 44. $1081-1110$. 
Lindemann-Matthies, P. \& Kamer, T. (2005). The influence of an interactive educational approach on zoo visitors' learning in a Swiss zoo. Science Education, 90. 296 315.

Loston, A.W., Steffan, P. L., \& McGee, S. (2005). NASA education: using inquiry in the classroom so that students see learning in a whole new light. Journal of Science Education and Technology, 14(2), 148-154.

McCarthy, C. B. (2005). Effects of thematic-based, hands-on science teaching versus a textbook approach for students with disabilities. Journal of Research in Science Teaching, 42. $245-263$.

Michigan Department of Labor and Economic Growth. (2007). June jobless rates increase in most of Michigan's regional labor markets, http://www.michigan.gov

Michigan Economic Development Corporation. (2007). Michigan population by county. Lansing, MI, http://www.michigan.gov

Moje, E. B., Cooazo, T., Carrillo, R., \& Marx, R. W. (2001). "Maesto, what is 'quality'?": Language, literacy, and discourse in project-based science. Journal of Research in Science Teaching, 38. 469 - 498.

Nuthall, G. (2000a). The role of memory in acquisition and retention of knowledge in science and social studies unit. Cognition and Instruction, 18, 83 - 139.

Nuthall, G. (2000b). The anatomy of memory in the classroom: Understanding how students acquire memory processes from classroom activities in science and social studies units. American Educational Research Journal. 37, 247 - 304.

Schierz, Z. \& Oren, M. (2006). How to change students' images of science and technology. Science Education, 90. 965 - 985. 
State of Michigan, (2007). Free and reduced lunch counts. Center for Educational Performance and Information, Lansing, MI, http://www.michigan.gov U. S. Census Bureau, (2006). Population Division and Housing and Household Economic Statistics Division, Washington, D.C., http://www.census.gov/population/pop-profile/dynamic/PopDistribution.pdf

U.S. Department of Education, Office of the Deputy Secretary, (2004). No Child Left Behind: A Toolkit for Teachers, Washington, D.C., p. 40.

U.S. Department of Education, Office of the Deputy Secretary, (2006). No Child Left Behind: Strengthening education: meeting the challenge of a changing world, Washington D.C., para. 2.

West Point Bridge Designer Software, (2007). http://bridgecontest.usma.edu/

Wu, H. (2003). Linking the microscopic view of chemistry to real-life experiences: Intertextuality in a high-school science classroom. Science Education, 87. 868 891.

Zitzevits, P. and Neff, R. (1995). Physics: Principals and problems. New York: Glencoe/McGraw Hill. 
(This page is deliberately blank.) 


\section{Appendix A: Michigan Dept. of Ed. Standards and Benchmarks for High School}

\begin{tabular}{|c|c|c|c|c|}
\hline Strand & Standard & Benchmark & Activities & Activity Description \\
\hline $\begin{array}{c}\text { Math II: } \\
\text { Variability and Change }\end{array}$ & $\begin{array}{l}\text { II: Geometry and } \\
\text { Measurement } \\
\text { III: Measurement } \\
\text { III: Measurement }\end{array}$ & $\begin{array}{l}\text { 4: Draw and construct shapes in } 2 \\
\text { and } 3 \text { dimensions and analyze } \\
\text { 1: Select and use the proper } \\
\text { measuring tools } \\
\text { 2: Apply measurements } \\
\text { 5: Use trigonometric ratios }\end{array}$ & $\begin{array}{l}5,6,7,9 \\
5,6,7,8 \\
4,5,6\end{array}$ & $\begin{array}{l}\text { Students required to design draw, and construct their own bridges. } \\
\text { Requires production of scale drawings and accurate construction } \\
\text { following their design drawings. } \\
\text { Students required to make accurate measurements and use proper } \\
\text { measuring devices. Students will measure lengths, angles, and mass, } \\
\text { in some cases, student must estimate measurements to construct } \\
\text { bridges. } \\
\text { Students required to use trigonometric ratios to complete calculations } \\
\text { of forces on bridges and to aid overall bridge design. }\end{array}$ \\
\hline $\begin{array}{l}\text { Math III: } \\
\text { Data Analysis and } \\
\text { Statistics }\end{array}$ & $\begin{array}{l}\text { I: Collection and } \\
\text { organization of } \\
\text { data }\end{array}$ & $\begin{array}{l}\text { 1: Collect data } \\
\text { 2: Organize data in charts and tables } \\
\text { 4: Identify data that is needed }\end{array}$ & $5,6,7,8,9,10$ & $\begin{array}{l}\text { Students required to identify, collect, and organize necessary data, } \\
\text { gathered through their own calculations, measurements, and } \\
\text { observations. Students are required to report their data in the lab } \\
\text { report. }\end{array}$ \\
\hline $\begin{array}{l}\text { Math V: } \\
\text { Numerical \& Algebraic } \\
\text { Operations and } \\
\text { Numerical Thinking }\end{array}$ & $\begin{array}{l}\text { I: Operations and } \\
\text { their properties } \\
\text { II: Algebraic and } \\
\text { Analytical } \\
\text { thinking }\end{array}$ & $\begin{array}{l}\text { 3: Describe properties with algebraic } \\
\text { expressions } \\
\text { 4: Accurately apply operations in } \\
\text { solving problems } \\
\text { 3: Solve linear equations }\end{array}$ & $4,5,6,7,10$ & $\begin{array}{l}\text { Students required to apply algebraic operations to solve and describe } \\
\text { the distribution of forces on their bridges. Students required to set up } \\
\text { and solve systems of equations. }\end{array}$ \\
\hline $\begin{array}{c}\text { Science I: } \\
\text { Construct New } \\
\text { Scientific and Personal } \\
\text { Knowledge }\end{array}$ & $\begin{array}{l}\text { I: Constructing } \\
\text { new scientific } \\
\text { knowledge }\end{array}$ & $\begin{array}{l}\text { 3: Design and conduct scientific } \\
\text { investigations } \\
\text { 6: Recognize limitations of } \\
\text { measuring device } \\
\text { 7: Gather information from books, } \\
\text { internet, etc. } \\
\text { 9: Reconstruct previously known } \\
\text { knowledge }\end{array}$ & $\begin{array}{l}6 \\
6,7 \\
1,3,6 \\
\text { All }\end{array}$ & $\begin{array}{l}\text { Students required to design a bridge and carry out all necessary steps } \\
\text { needed to prepare for building the bridge } \\
\text { Students required to measure and recognize how accurate their } \\
\text { measurements are. } \\
\text { Students required to find information from the internet and to become } \\
\text { acquainted with successful bridge design using the West Point Bridge } \\
\text { Builder Program } \\
\text { Students will build upon and reconstruct their previous knowledge of } \\
\text { bridges throughout the entire bridge unit. }\end{array}$ \\
\hline $\begin{array}{c}\text { Science IV: } \\
\text { Use Scientific } \\
\text { Knowledge from the } \\
\text { Physical Science in } \\
\text { Real-World Contexts }\end{array}$ & $\begin{array}{l}\text { III: Motion of } \\
\text { Objects }\end{array}$ & $\begin{array}{l}\text { 2: Describe force on an object } \\
\text { 3: Analyzed motion of an object }\end{array}$ & $2,3,4,5,6,9,10$ & $\begin{array}{l}\text { Students required to describe the types and amount of forces on } \\
\text { bridges. Students will analyze the motion of their bridges, the sum of } \\
\text { which should be equal to zero. }\end{array}$ \\
\hline
\end{tabular}


(This page deliberately blank) 


\section{Appendix B}

\section{Method of Joints and Sections}

\section{Method of Joints:}

For each of the following(on a separate piece of paper):

1. Label each joint and member.

2. Label all forces acting on the bridge indicated by arrows.

3. Draw free-body diagrams for each joint. (for the first 4 joints)

4. Calculate the amount of force on each member. (for the first 4 joints)

5. Determine whether each member is in tension or compression.

1. $18 \mathrm{~N}$ load applied to the bridge half shown below.

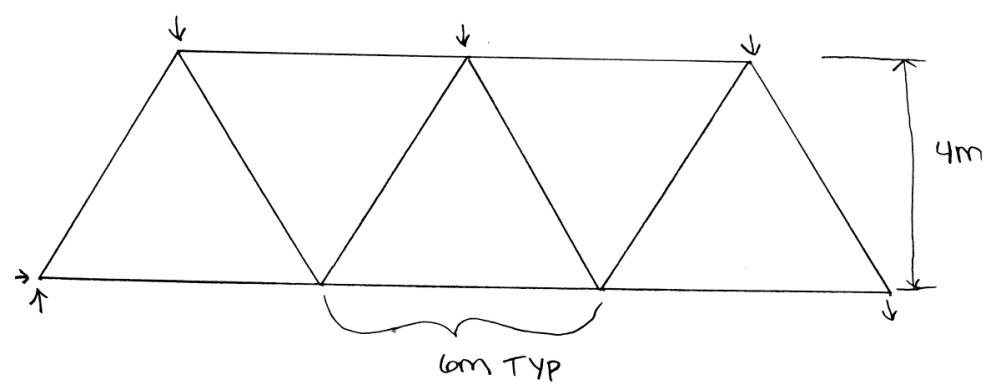

2. $30 \mathrm{~N}$ load applied to the bridge half shown below.

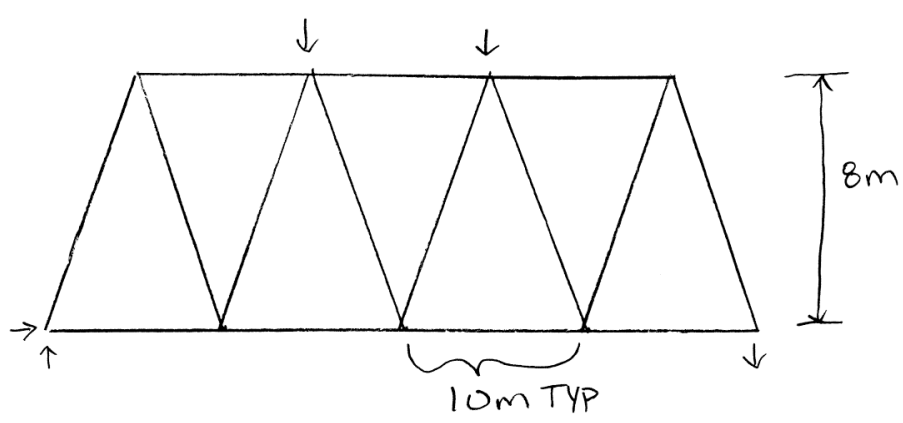

3. $8 \mathrm{~N}$ load applied to the bridge half shown below.

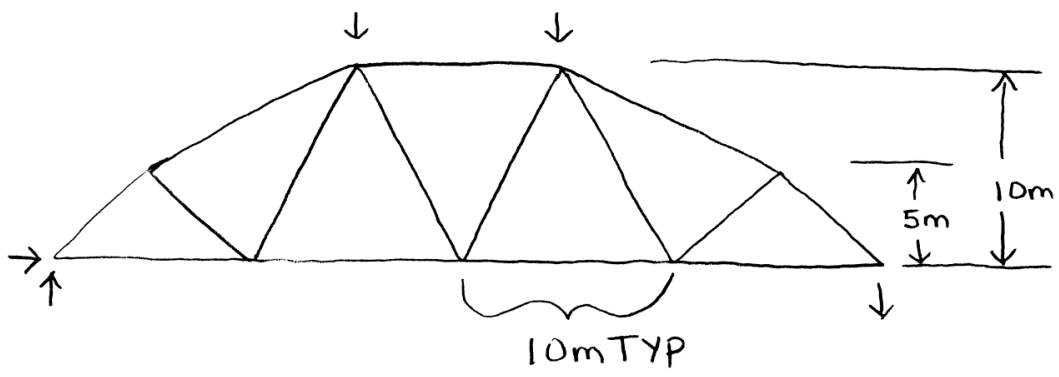




\section{Method of Joints: Answer Key}

For each of the following (on a separate piece of paper):

1. Label each joint and member.

2. Label all forces acting on the bridge indicated by arrows.

3. Draw free-body diagrams for each joint. (for the first 4 joints)

4. Calculate the amount of force on each member. (for the first 4 joints)

5. Determine whether each member is in tension or compression.

1. $18 \mathrm{~N}$ load applied to the bridge half shown below.

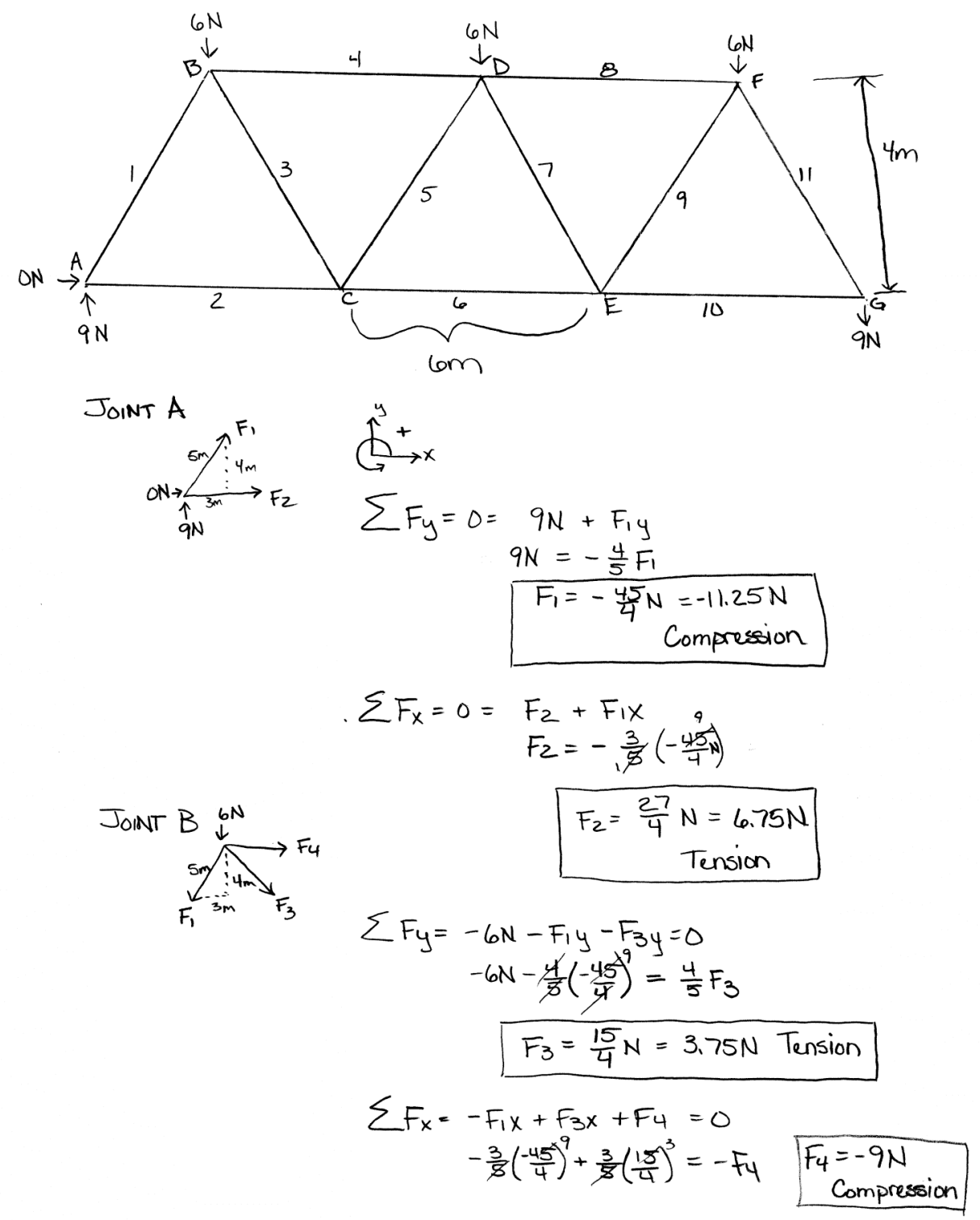


2. $30 \mathrm{~N}$ load applied to the bridge half shown below.
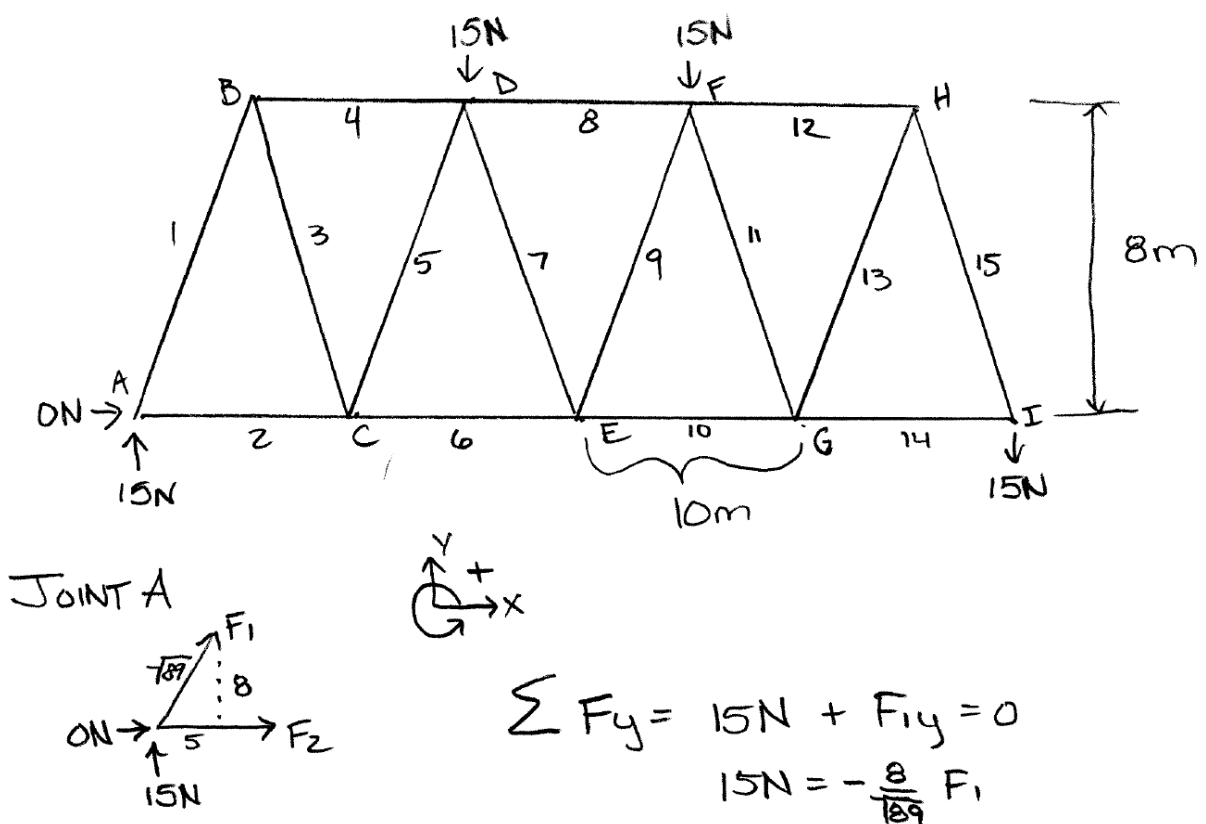

$$
\begin{aligned}
& \stackrel{\hat{S}^{y}+}{\sum} F_{y}=15 N+F_{1 y}=0 \\
& 15 N=-\frac{8}{189} F_{1} \\
& F_{1}=-\frac{15 \sqrt{89}}{8} \mathrm{~N}=-17.7 \mathrm{~N}
\end{aligned}
$$

Compression

$$
\begin{aligned}
& \sum F_{x}= F_{2}+F_{1 x}=0 \\
& F_{2}=-\frac{5}{\sqrt{19}}\left(-\frac{15 \sqrt{89}}{8}\right) \\
& F_{2}=\frac{75}{8} N=9.4 \mathrm{~N} \\
& \text { Tension }
\end{aligned}
$$

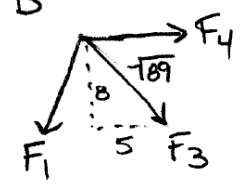

$$
\begin{aligned}
& \sum F_{y}=-F_{1 y}-F_{3 y}=0 \\
& -\frac{8}{\sqrt{89}}\left(-\frac{15 \sqrt{89}}{8}\right)=\frac{8}{189} F_{3} \\
& F_{3}=\frac{15 \sqrt{89}}{8} \mathrm{~N}=17.7 \mathrm{~N} \\
& \sum F_{x}=-F_{1 x}+F_{3 x}+F_{4} \\
& -\frac{5}{189}\left(-\frac{15 \sqrt{89}}{8}\right)+\frac{5}{189}\left(\frac{15 \sqrt{89}}{8}\right)=-F_{4} \\
& F_{4}=-\frac{75}{4} \mathrm{~N}=-18.8 \mathrm{~N}
\end{aligned}
$$

Compression

67 
3. $8 \mathrm{~N}$ load applied to the bridge half shown below.

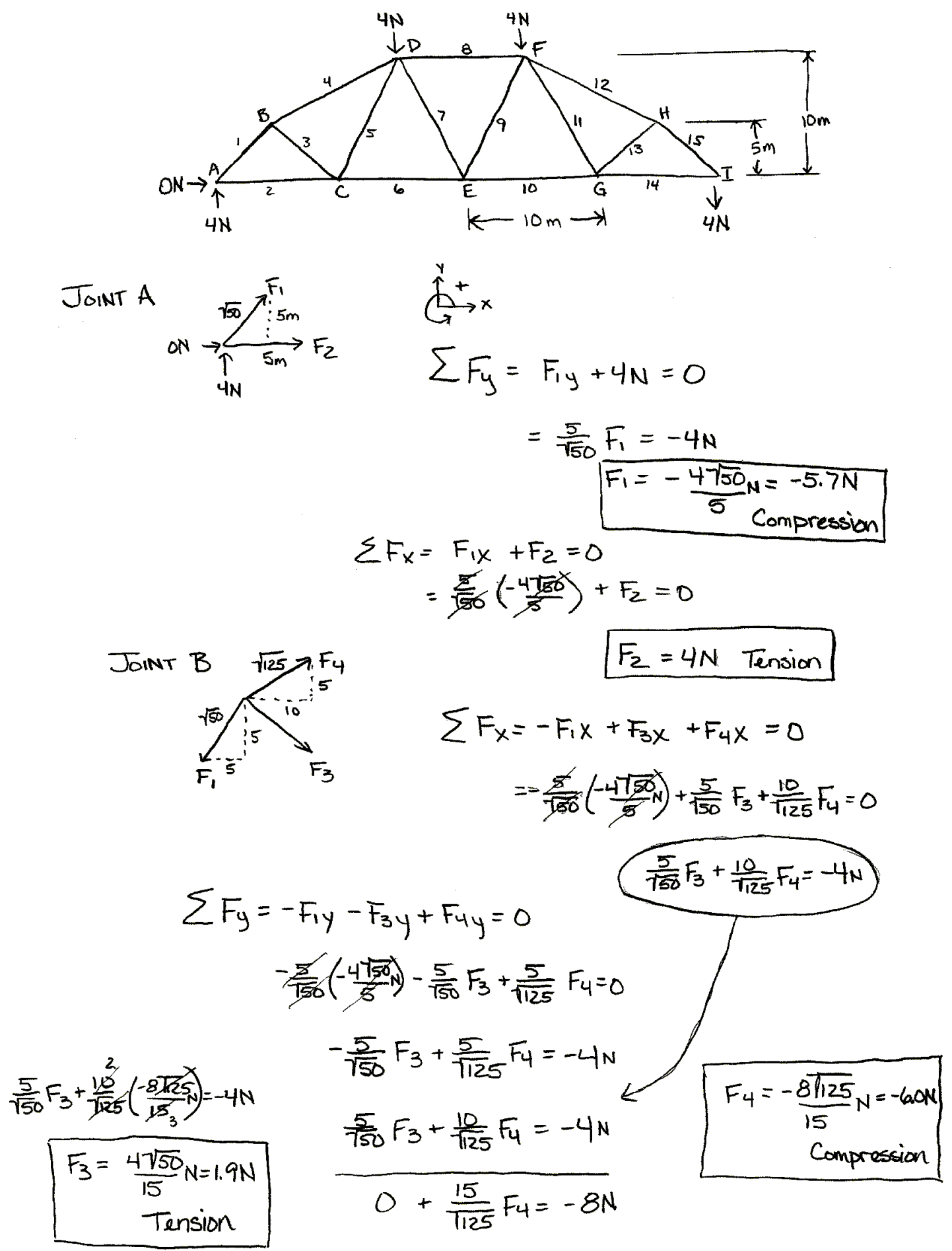




\section{Method of Sections:}

For each of the following using the Method of sections (on a separate piece of paper):

1. Label each joint and member.

2. Label all forces acting on the bridge indicated by arrows.

3. Draw free-body diagrams for the section indicated by the break in the bridge.

4. Calculate the amount of force on each of the three members shown at the break.

5. Determine whether each member is in tension or compression.

1. $30 \mathrm{~N}$ load applied to the bridge half shown below.

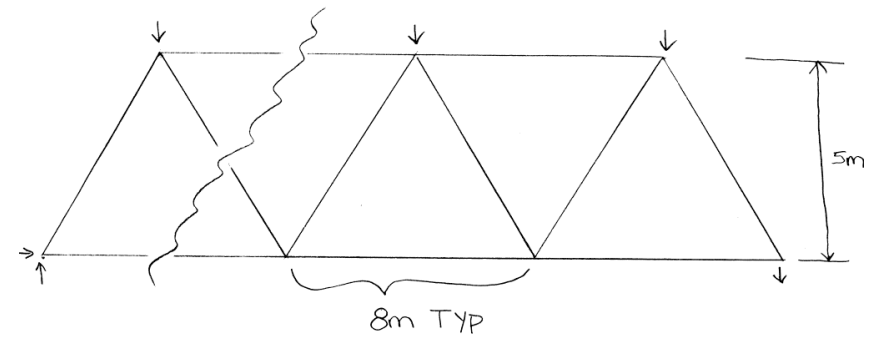

2. $12 \mathrm{~N}$ load applied to the bridge half shown below.

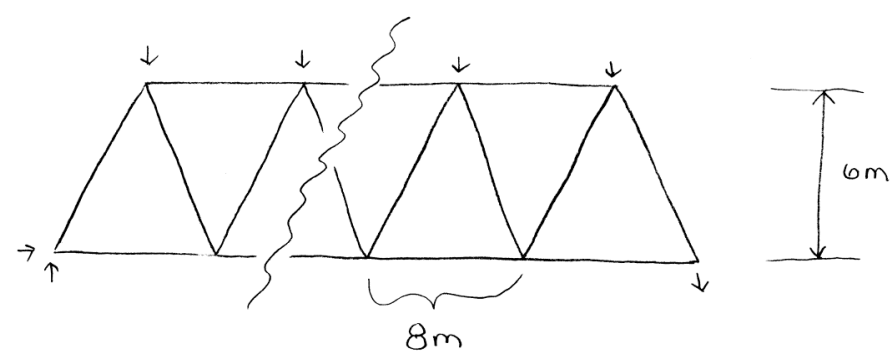

3. $10 \mathrm{~N}$ load applied to the bridge half shown below.

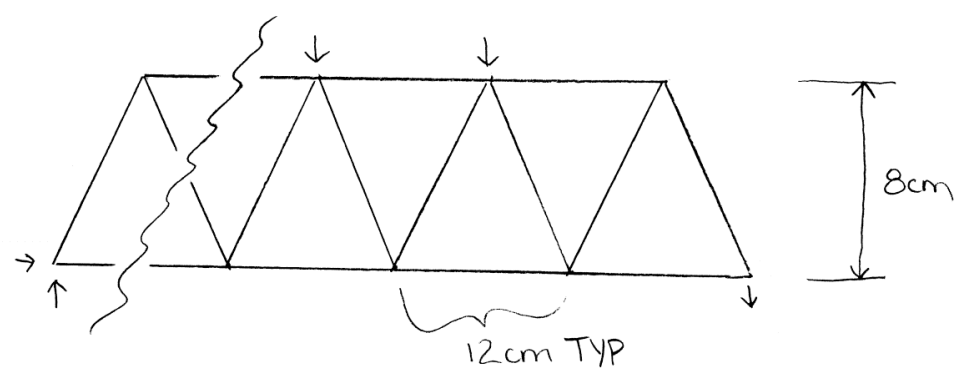




\section{Method of Sections: Answer Key}

For each of the following using the Method of sections (on a separate piece of paper):

1. Label each joint and member.

2. Label all forces acting on the bridge indicated by arrows.

3. Draw free-body diagrams for the section indicated by the break in the bridge.

4. Calculate the amount of force on each of the three members shown at the break.

5. Determine whether each member is in tension or compression.

1. $30 \mathrm{~N}$ load applied to the bridge half shown below.

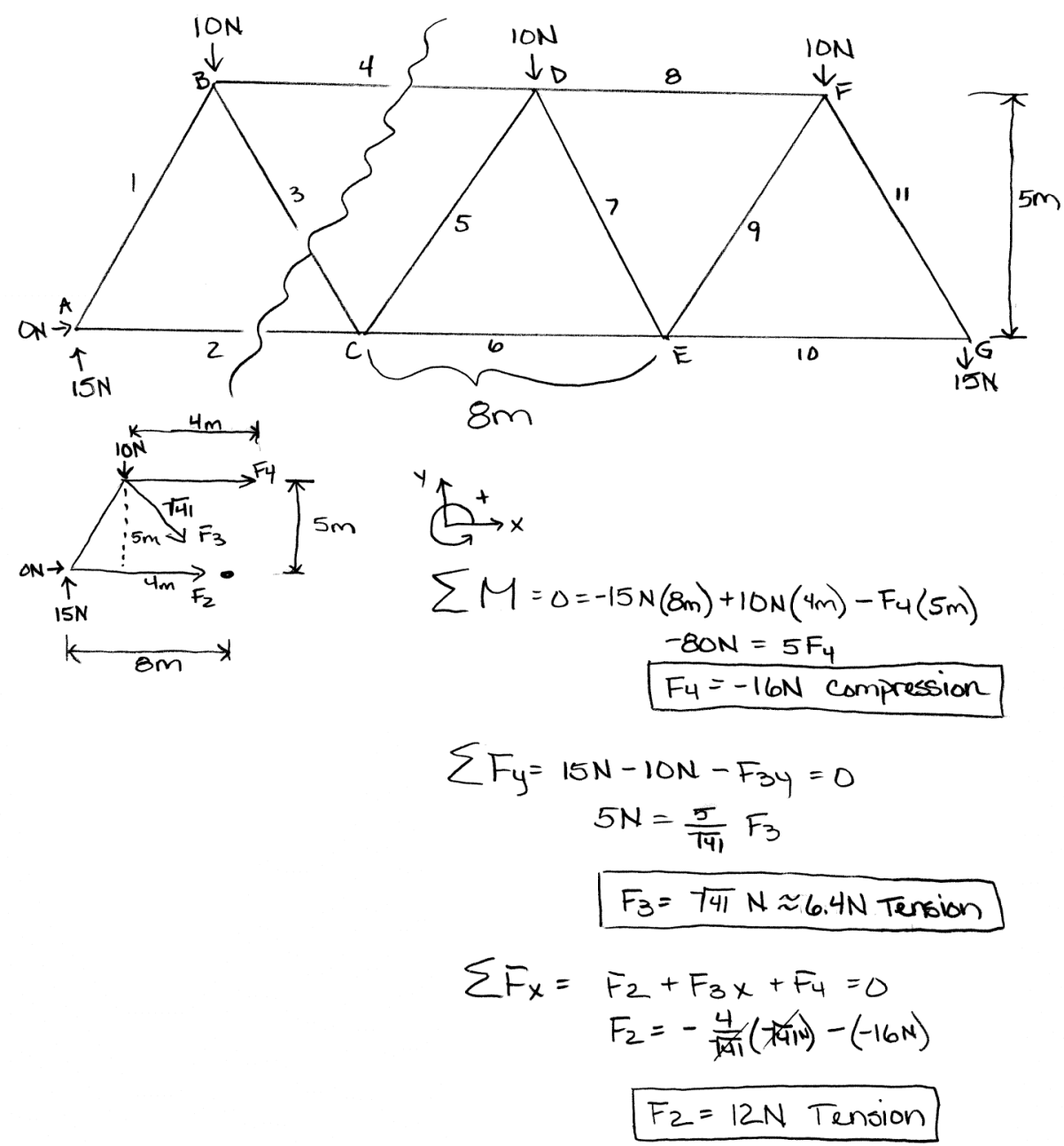


2. $12 \mathrm{~N}$ load applied to the bridge half shown below.

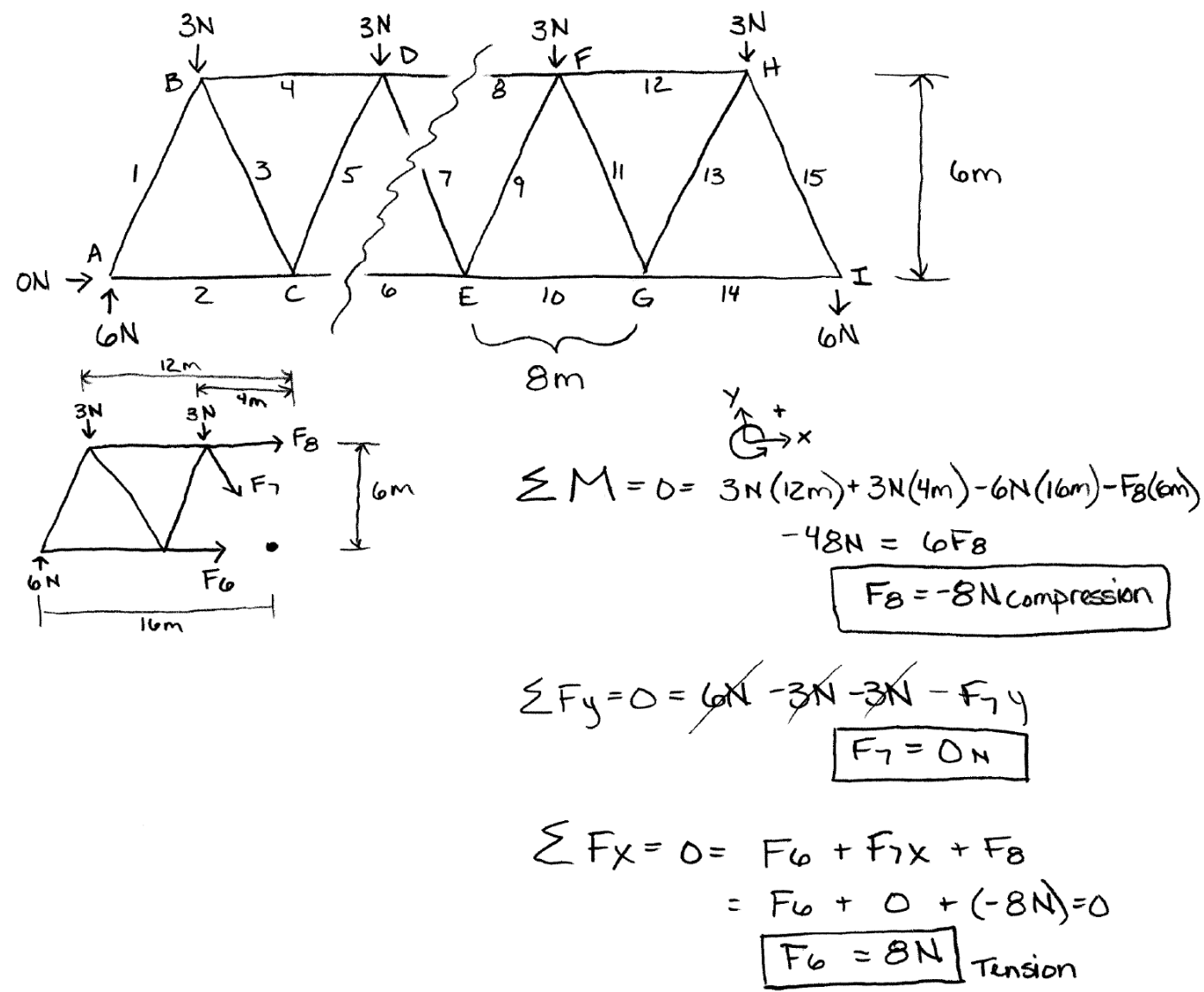


3. 10N load applied to the bridge half shown below.
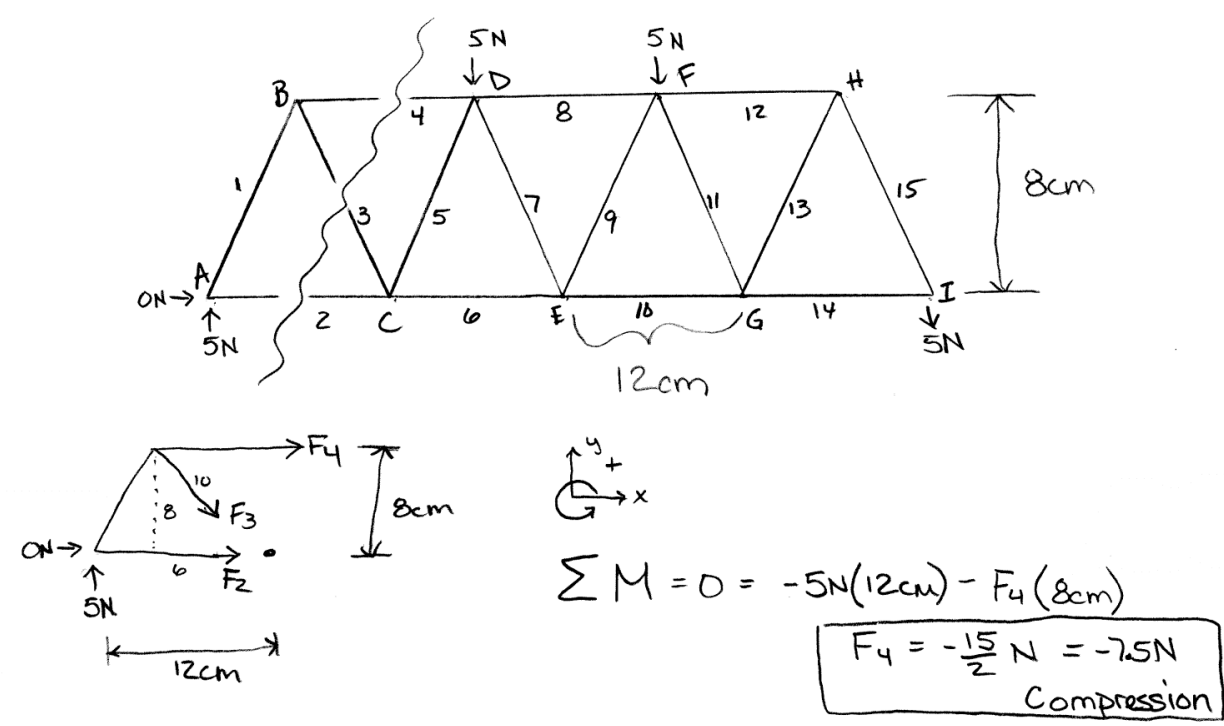

$$
\begin{aligned}
& \sum F_{y}=0=5 N-F_{3 y} \\
& 5 N=\frac{8}{105} F_{3} \\
& F_{3}=\frac{25}{4} N \approx 6.3 N \\
& \text { Tension }
\end{aligned}
$$

$$
\begin{aligned}
& \sum F_{x}=0= F_{2}+F_{3} x+F_{4} \\
& F_{2}=-\frac{6}{10}\left(\frac{25}{4} N\right)-\left(-\frac{15}{2} N\right) \\
& F_{2}=-\frac{35}{8} N \approx-4.4 N \\
& \text { Compression }
\end{aligned}
$$




\section{Appendix C}

\section{Handouts for Students}

\section{Bridge Specifications}

1. Your bridge must be a through-truss bridge.

2. It must span $60 \mathrm{~cm}$.

3. Its width must be $10 \mathrm{~cm}$ for the roadway (interior width) and must not exceed a total width (exterior width) of $12 \mathrm{~cm}$.

4. It must be between $5 \mathrm{~cm}$ and $20 \mathrm{~cm}$ in height.

5. The bridge must be able to carry $4 \mathrm{~kg}$, which will be placed in the center of the bridge.

6. The bridge that is the lightest, able to carry all of the weight for at least 1 minute, and is the most creative in design will win the competition.

7. You may only use the materials listed in the materials list.

\section{Your grade will be based on the following...}

1. Weight of your bridge versus the amount of creativity in your design. Ex: a simple design would be expected to have a lighter weight than a more complex design.

2. Does your bridge hold the weight?

3. Did you finish all calculations prior to the start of constructing your bridge?

4. Did you follow your bridge design accurately when constructing your bridge?

5. Audience survey including: appearance, creativity, practicality, and trustworthiness.

6. Does your bridge meet the specifications given above?

\section{Bridge Hints:}

1. Long compression members buckle easily.

2. You should try to have 3 or more joints on each half of your bridge touch the book.

3. Make sure you allow your bridge to dry thoroughly.

4. When designing your bridge, remember $(2 \mathrm{x} \#$ of joints $=\#$ of members +3$)$

5. Use rubber cement or white glue only!

6. Make sure your compressions members are not twisted and that they are extra long so you have a place to glue when connecting them.

7. Put gussets over your joints to help them stay together.

8. Use attached table to determine appropriate member size.

9. The load will be distributed over 2 bridge halves! 
(This page is deliberately blank.) 


\section{Appendix D}

\section{Surveys}

\section{Group Work Survey}

Rate Your Group Work.

Group Number:

Your Name:

Group member(s):

These will be confidential High

Low

1. How well did your group work together?

$\begin{array}{llllll}5 & 4 & 3 & 2 & 1 & 0\end{array}$

2. Do you feel that you and your team built your bridge to the best of your abilities?

$\begin{array}{llllll}5 & 4 & 3 & 2 & 1 & 0\end{array}$

3. What was your amount of effort on this bridge project?

$\begin{array}{lllllll}5 & 4 & 3 & 2 & 1 & 0\end{array}$

4. What was the amount of your partner's effort on this bridge project?

$\begin{array}{lllllll}5 & 4 & 3 & 2 & 1 & 0\end{array}$

4b. If you had more than one partner, what was the second partner's amount of effort?

$\begin{array}{lllllll}5 & 4 & 3 & 2 & 1 & 0\end{array}$

5. Do you feel that you built your bridge to the specifications that you calculated?

$\begin{array}{llllll}5 & 4 & 3 & 2 & 1 & 0\end{array}$

Comments: 


\section{Observer Survey}

Please rate each bridge based on the following:

Group number

1. Creativity:

$\begin{array}{lllllr}\text { High } & & & & & \text { Low } \\ 5 & 4 & 3 & 2 & 1 & 0\end{array}$

2. Appearance:

$\begin{array}{llllll}5 & 4 & 3 & 2 & 1 & 0\end{array}$

3. Practicality:

$\begin{array}{llllll}5 & 4 & 3 & 2 & 1 & 0\end{array}$

4. Trustworthiness (would you use this bridge):

$\begin{array}{llllll}5 & 4 & 3 & 2 & 1 & 0\end{array}$

5. Overall Score:

$\begin{array}{llllll}5 & 4 & 3 & 2 & 1 & 0\end{array}$

Comments: 


\section{Student Survey}

Name:

This is not part of your grade.

1. Did you enjoy doing this unit?

$\begin{array}{llllrr}\text { High } & & & & \text { Low } \\ 5 & 4 & 3 & 2 & 1 & 0\end{array}$

2. Do you feel that the unit was easier to understand than other units?

$\begin{array}{llllll}5 & 4 & 3 & 2 & 1 & 0\end{array}$

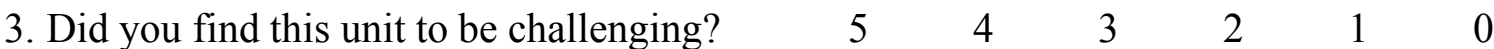

4. Would you like to do other units that involved these types of activities?

$\begin{array}{llllll}5 & 4 & 3 & 2 & 1 & 0\end{array}$

5. Was your overall feeling to this unit positive? $\quad \begin{array}{llllllll}4 & 4 & 3 & 2 & 1 & 0\end{array}$

Please list any other comments you have regarding this unit: 
Group Number

Members

Bridge Mass:

Bridge Height:

Bridge Width:

Inner Outer

Bridge Length:

Time:

Weight Held:

Creativity:

Neatness:

Built to design/calculations:

Visually pleasing:

Appears stable:

Appropriate height:

Appropriate width (inner):

Appropriate width (outer):

Appropriate length:

Holds total weight:

Reasonable mass for design:

Holds weight for 1 minute:
High

5

5

5

5

5

5

5

5

5

5

5

5

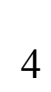

4

4

4

4

4

4

4

4

4

4

4

3

$\begin{array}{rrr}2 & 1 & \text { Low } \\ 2 & 1 & 0\end{array}$

$\begin{array}{llll}3 & 2 & 1 & 0\end{array}$

$\begin{array}{llll}3 & 2 & 1 & 0\end{array}$

$\begin{array}{llll}3 & 2 & 1 & 0\end{array}$

$\begin{array}{llll}3 & 2 & 1 & 0\end{array}$

$\begin{array}{llll}3 & 2 & 1 & 0\end{array}$

$\begin{array}{llll}3 & 2 & 1 & 0\end{array}$

$\begin{array}{llll}3 & 2 & 1 & 0\end{array}$

Total points from above:

Points from observers:

Points from team members:

Score: 


\section{Appendix E}

\section{Pre-Unit Test}

1. Name three types of bridges.
a.
b.
c.

2. What is the best shape for a truss?

3. Give a brief definition for the following terms:
a. Tension

b. Compression

4. Name three people who would be involved in building a bridge and explain how they might be involved.

a.

b.

c.

5. If $12 \mathrm{~N}$ is placed on the half of bridge shown below, label the amount of force that would be felt at each point of contact indicated by the arrows and give the number of members.

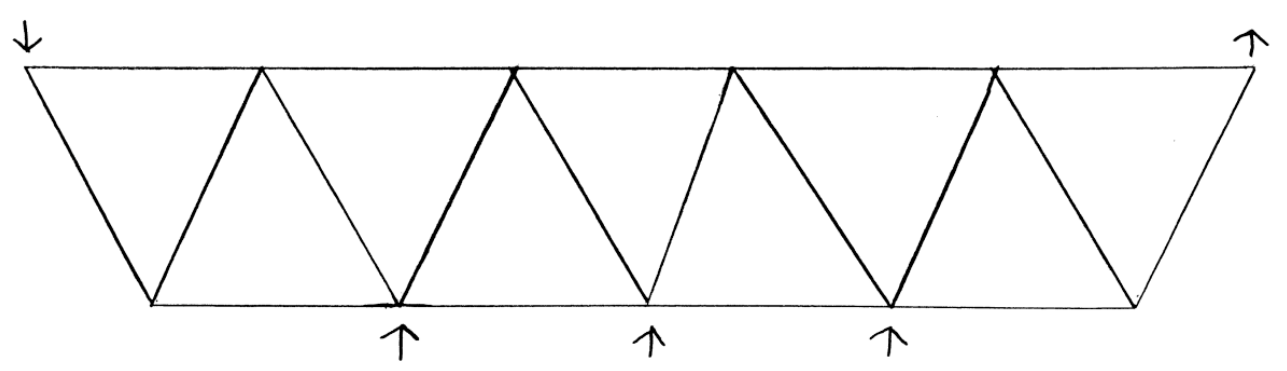




\section{Pre-unit Test Answer Key}

Students receive 5 points of extra credit for completing all questions even if incorrect.

1. Possible answers might be: Truss, Suspension, Arch, Girder, Cable, etc.

2. Triangle

3. Possible answers would include

a. Tension: Pulling or stretching of something due to an applied force.

b. Compression: Pushing or compacting something due to an applied force.

4. Possible answers might include the following

a. Owner: Person or persons who decide that a bridge is wanted, gives the general ideas of what is wanted.

b. Engineer: Designs and ensures plans are followed.

c. Local or state government: Set ordinances and laws regarding bridge construction

5. There are 19 members on the bridge, the force placement would be as follows

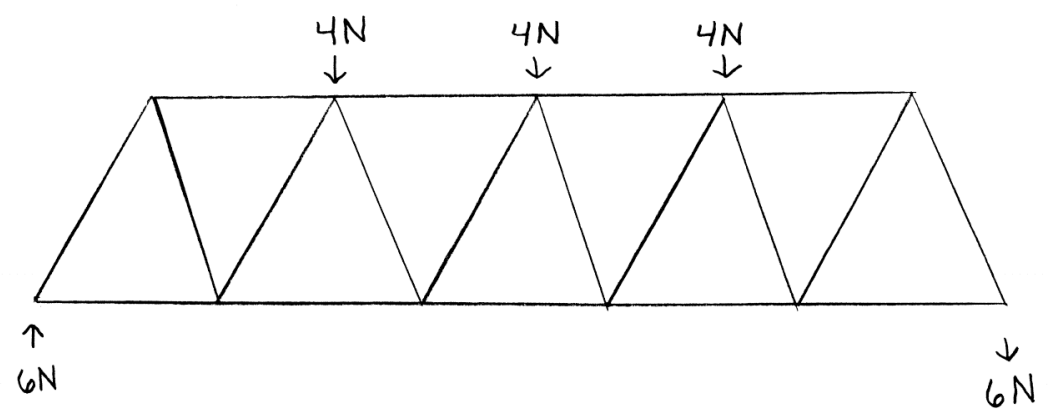

\section{Pretest Grading Rubric: 12 points possible}

1. 3 points possible: 1 point for each correct bridge type up to 3 points.

2. 1 point possible: 1 point for correct shape

3. 2 points possible: 1 point given for each correct answer

4. 3 points possible: 1 point given for each person(s) with correct explanation up to 3 points.

5. 3 points possible: 1 point for correctly labeling top arrows, 1 point for correctly labeling the bottom arrows, 1 point given for correct number of members. 


\section{Appendix F}

\section{Bridge Unit Posttest}

Use additional paper if necessary.

1. What is the best shape for a truss? Why?

2. Name three types of bridges other than a Truss bridge.

a.

b.

c.

3. When calculating forces on bridge members, how can you tell when the member is in tension?

4. Name three people who would be involved in building a bridge and explain how they might be involved.
a.
b.
c.

5. What did a member colored red indicate on the West Point Bridge Builder Program?

6. What is the name of the point where 2 or more bridge members meet?

7. If $15 \mathrm{~N}$ is the load placed on one half (one side shown) of the bridge below in question 9, how much load is there on the entire bridge?

8. How many members are on the bridge below in question 9 ? 
9. If $15 \mathrm{~N}$ is placed on the half of bridge shown below, label the amount of force that would be at each arrow (indicating areas where the force is applied).

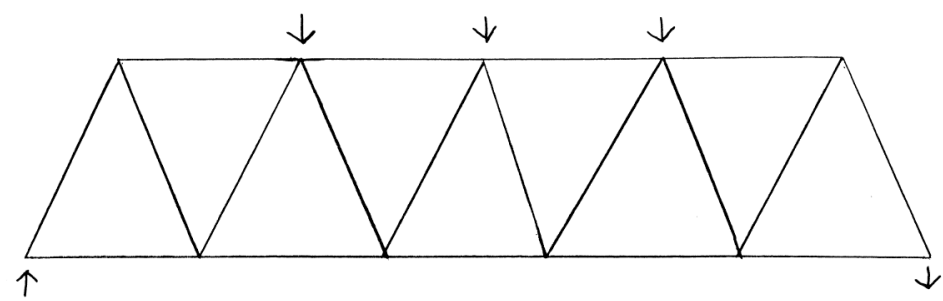

10. Use the method of joints to calculate the forces on members $1,2,3$, and 4 of the bridge below.

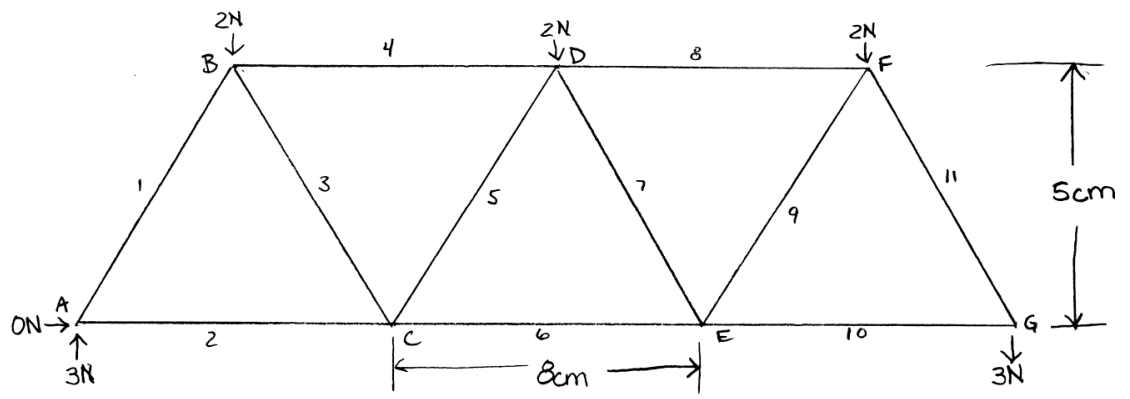


11. If a $12 \mathrm{~N}$ load is applied to the half of bridge shown below, label all forces acting on the bridge indicated by the arrows. Use the method of sections to calculate the forces on members 2,3 , and 4 on the bridge below.

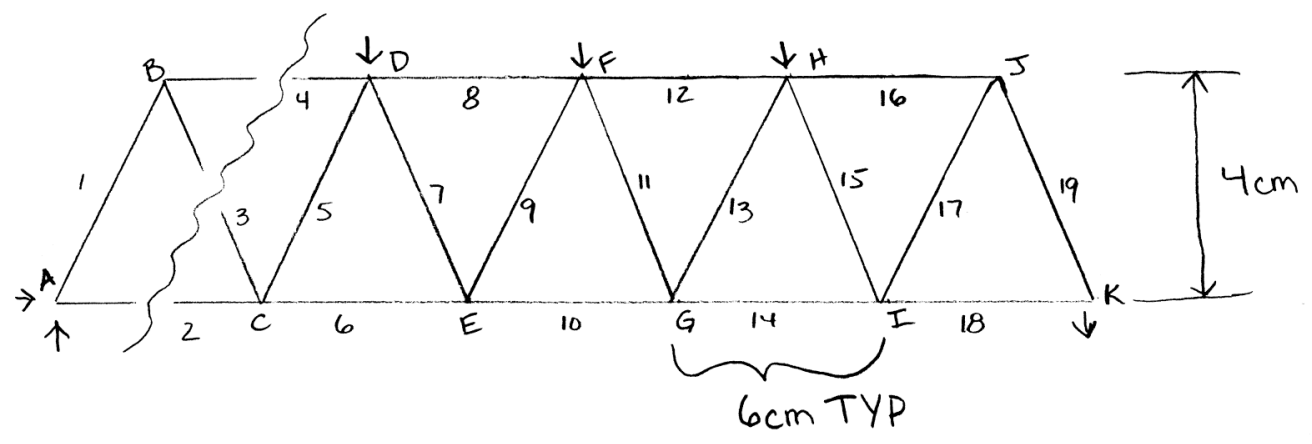




\section{Bridge Unit Test: Answer Key}

1. What is the best shape for a truss? Why?

Triangular is the best shape for a truss because applied forces are evenly distributed on the members.

2. Name three types of bridges other than a Truss bridge.

Example answers might include Suspension, Girder, Cable Stay, Deck, Arch.

3. When calculating forces on bridge members, how can you tell when the member is in tension? The force equals a positive number.

4. Name three people who would be involved in building a bridge and explain how they might be involved.

Example answers would be Engineer, Bank, Project Manager, Owner (Community), Insurance Agency, Contractor, Government... with explanations of involvement.

5. What did a member colored red indicate on the West Point Bridge Builder Program?

Members that were colored red indicate compression.

6. What is the name of the point where 2 or more bridge members meet?

The place where two or more members meet is called a Joint.

7. If $15 \mathrm{~N}$ is the load placed on one half (one side shown) of the bridge below in question 9 , how much load is there on the entire bridge?

There would be $30 N$ of force on the entire bridge.

8. How many members are on the bridge below in question 9 ?

There are 19 bridge members.

9. If $15 \mathrm{~N}$ is placed on the half of bridge shown below, label the amount of force that would be at each arrow (indicating areas where the force is applied).

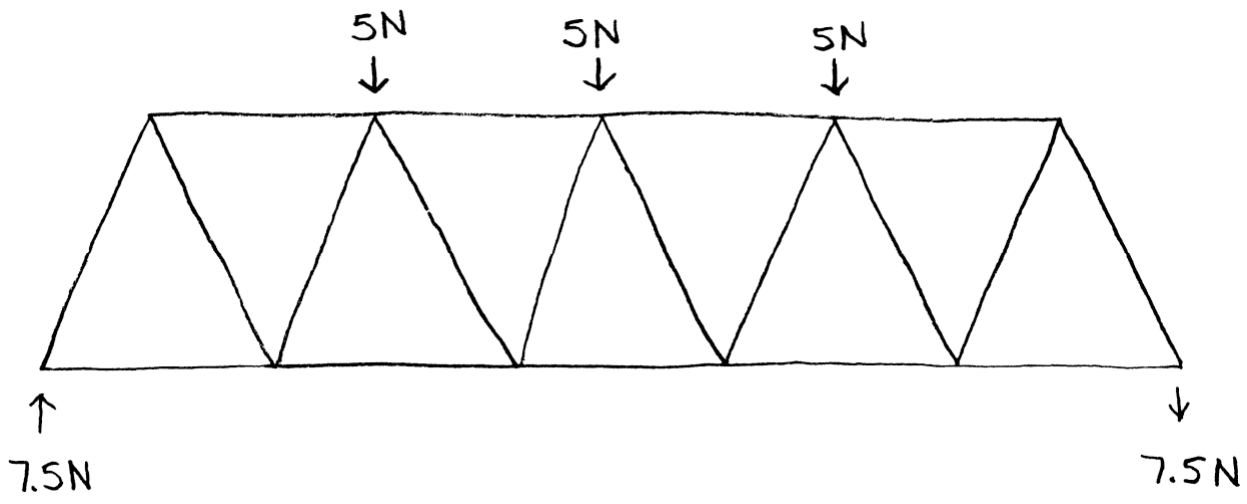


10. Use the method of joints to calculate the forces on members $1,2,3$, and 4 of the bridge below.

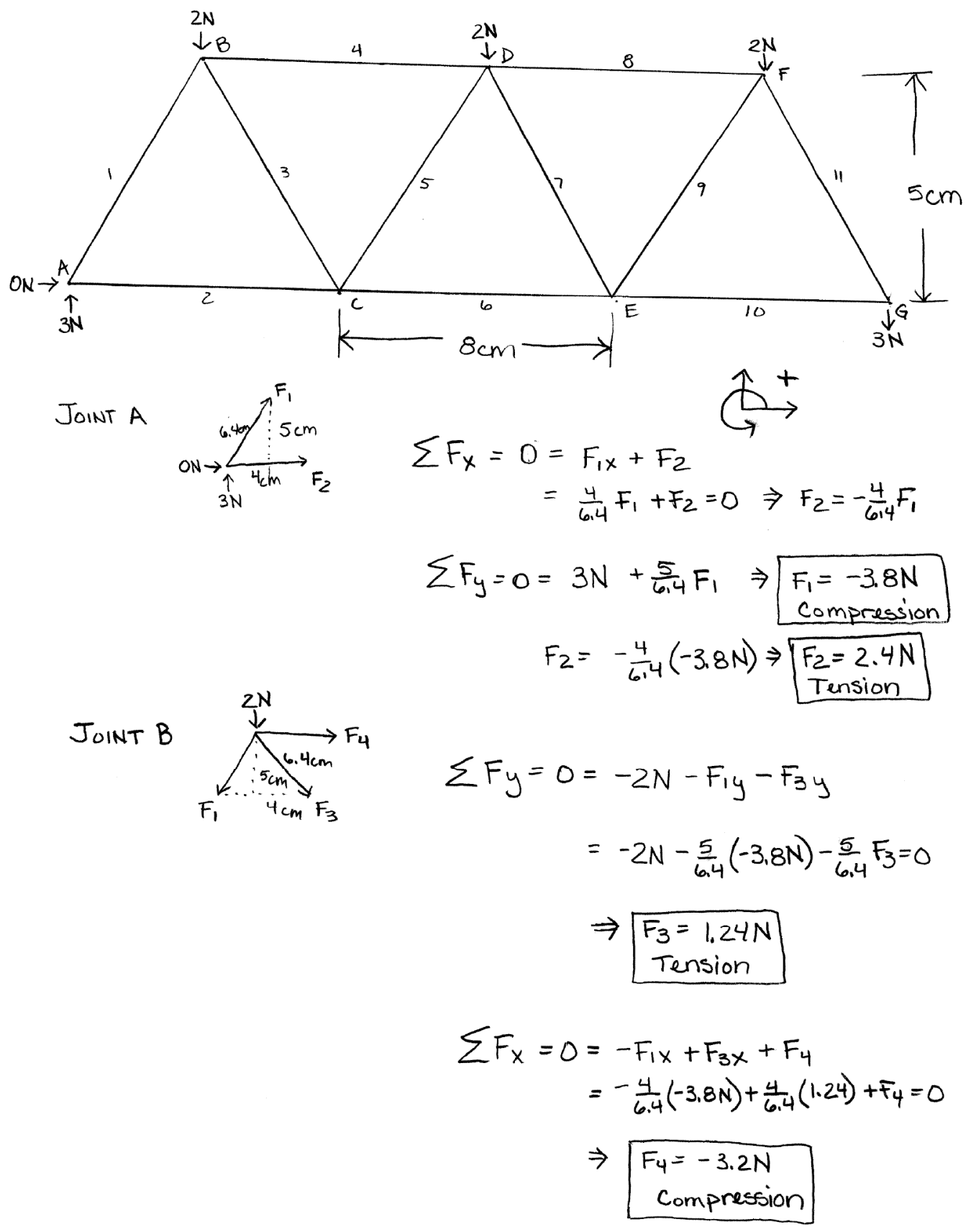


11. Use the method of sections to calculate the forces on members 2,3 , and 4 on the bridge below.

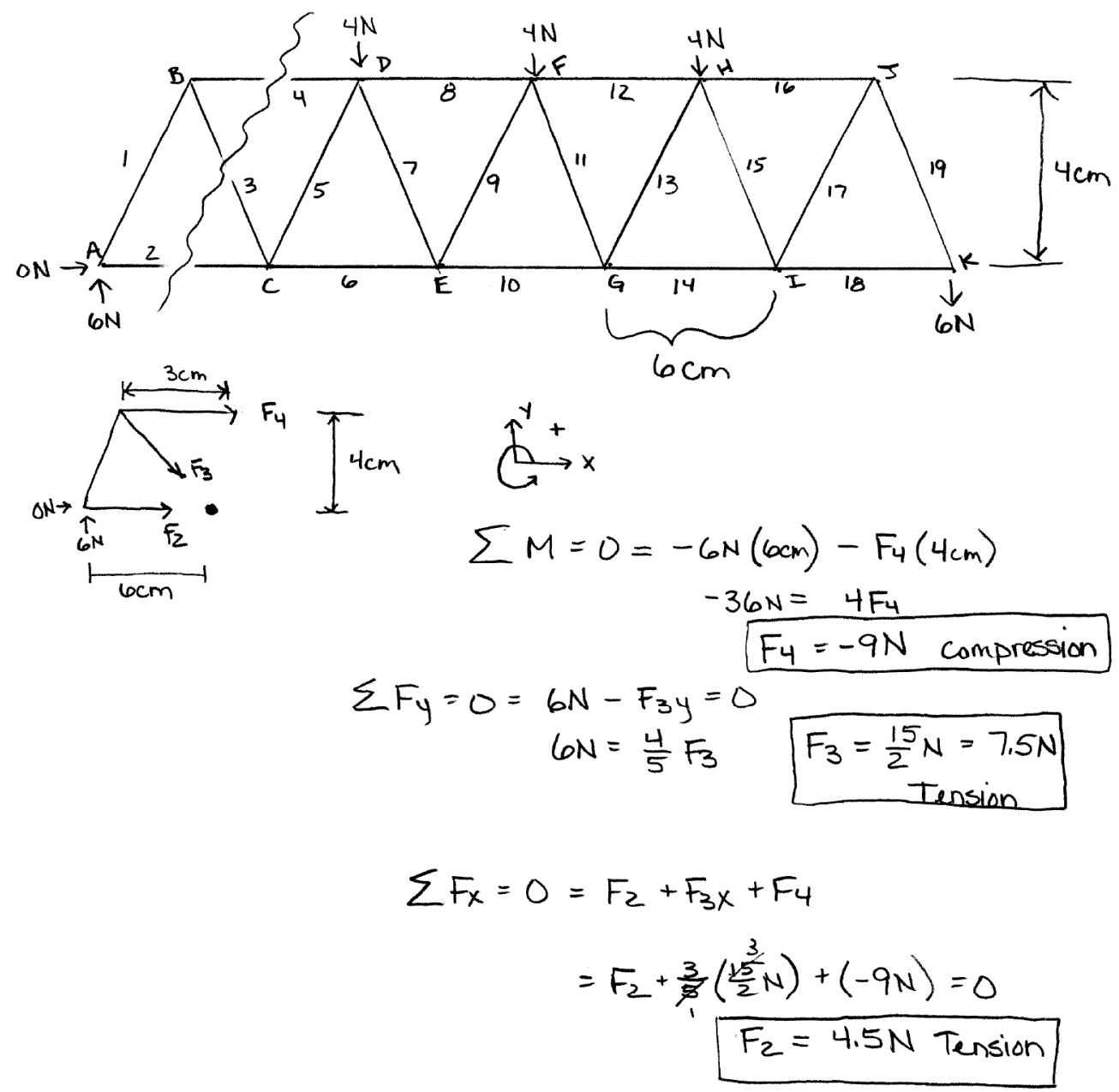




\section{Bridge Unit Test Grading Rubric: 60 points possible}

1. 2 points possible: 1 point for correct shape, 1 point for correct reason

2. 3 points possible: 1 point for each correct bridge type given up to 3 points

3. 1 point possible: Student must know that force should be positive.

4. 6 points possible: 1 point for each correct person(s) up to 3,1 point for each correct involvement explanation up to 3 points.

5. 1 point possible: Student must know that force colored red means compression.

6. 1 point possible: Student must state that members meet at a Joint.

7. 1 point possible: Student must know that the force would be $30 \mathrm{~N}$.

8. 1 point possible: Student must say there are 19 members on the bridge.

9. 2 points possible: 1 point for correctly labeling the top arrows, 1 point for correctly labeling the bottom arrows.

10. 24 points possible: 6 points for correctly drawing the free-body diagrams; including member lengths, forces, and coordinate system indicating positive direction; 14 points for correctly calculating the forces on each member; including correctly setting up equations 4 pts, correctly inserting all forces and distances/ratios 4pts, and correct calculations 4pts, no mistakes in calculations 2pts; 1 point for each correct label of compression or tension up to 4 points.

11. 18 points possible: 2 points for correctly labeling the forces at arrows; 3 points for correctly drawing the free-body diagram; including member lengths, forces, and coordinate system indicating positive direction; 10 points for correctly calculating the forces on each member; including correctly setting up equations 3 pts, correctly inserting all forces and distances/ratios 3 pts, and correct calculations 3 pts, no mistakes in calculations $1 \mathrm{pt} ; 1$ point for each correct label of compression or tension up to 3 points. 
(This page is deliberately blank.) 


\section{Appendix G}

\section{Traditional Unit}

\section{Example Practice Problems from Merrill Physics: Principles and Problems}

1. An asteroid revolves around the sun with a mean average orbital radius twice that of Earth's. Predict the period of the asteroid in earth years.

2. Calculate the velocity that a satellite shot from Newton's cannon must have in order to orbit Earth, $150 \mathrm{~km}$ above its surface. Then calculate how long it would take for the satellite to return to the cannon in seconds and minutes.

3. We consider the sun to be a satellite of our galaxy, the Milky Way. The sun revolves around the center of the galaxy with a radius of $2.2 \times 10^{20} \mathrm{~m}$. The period of one rotation is $2.5 \times 10^{8}$ years. a) Find the mass of the galaxy. b) Assuming the average star in the galaxy has the mass of the sun, find the number of stars. c) Find the speed with which the sun moves around the center of the galaxy.

4. Tom has a mass of $70.0 \mathrm{~kg}$ and Sally has a mass of $50.0 \mathrm{~kg}$. Tom and Sally are standing $20.0 \mathrm{~m}$ apart on the dance floor. Sally looks up and sees him. She feels an attraction. If the attraction is gravitation, find its size. Assume that both can be replaced by spherical masses.

5. Earth's gravitational field is $7.83 \mathrm{~N} / \mathrm{kg}$ at the altitude of the space shuttle. What is the size of the force of attraction between a student, mass of $45.0 \mathrm{~kg}$, and Earth? 


\section{Answer Key for Example Traditional Unit Problems}

1. $\left(\mathrm{T}_{\mathrm{a}} / \mathrm{T}_{\mathrm{E}}\right)^{2}=\left(\mathrm{r}_{\mathrm{a}} / \mathrm{r}_{\mathrm{E}}\right)^{3}$ with $\mathrm{r}_{\mathrm{a}}=2 \mathrm{r}_{\mathrm{E}}$

Thus, $\mathrm{T}_{\mathrm{a}}^{2}=\left(\mathrm{r}_{\mathrm{a}} / \mathrm{r}_{\mathrm{E}}\right)^{3} \mathrm{~T}_{\mathrm{E}}^{2}$

$$
=\left(2 r_{E} / r_{E}\right)^{3}(1 \mathrm{yr})^{2}=8 \mathrm{yr}^{2}, \mathrm{~T}_{\mathrm{a}}=2.8 \mathrm{yr}
$$

2. $\mathrm{v}=\bullet\left(\mathrm{GM}_{\mathrm{E}} / \mathrm{r}\right)=\hookrightarrow\left[\left(6.67 \times 10^{-11}\right)\left(5.98 \times 10^{24}\right) /\left(6.52 \times 10^{6}\right)\right]$

$=7.82 \times 10^{3} \mathrm{~m} / \mathrm{s}$

$$
\begin{aligned}
\mathrm{T} & =2 \pi \bullet\left(\mathrm{r}^{3} / \mathrm{GM}_{\mathrm{E}}\right) \\
& =2 \pi \bullet\left[\left(6.52 \times 10^{6} \mathrm{~m}\right)^{3} /\left(6.67 \times 10^{-11} \mathrm{Nm}^{3} / \mathrm{kg}^{2}\right)\left(5.98 \times 10^{24} \mathrm{~kg}\right)\right] \\
& =5.24 \times 10^{3} \mathrm{~s}=87.3 \mathrm{~min}
\end{aligned}
$$

3. a. Using $\mathrm{T}=2 \pi \bullet\left(\mathrm{r}^{3} / \mathrm{GM}\right)$ with

$$
\begin{aligned}
\mathrm{T} & =2.5 \times 10^{8} \mathrm{y}=7.9 \times 1015 \mathrm{~s} \\
\mathrm{M} & =4 \pi^{2} \mathrm{r}^{3} / \mathrm{GT}^{2} \\
& =4 \pi^{2}\left(2.2 \times 10^{20} \mathrm{~m}\right)^{3} /\left[\left(6.67 \times 10^{-11} \mathrm{Nm}^{2} / \mathrm{kg}^{2}\right) 97.9 \times 10^{15} \mathrm{~s}\right)^{2} \\
& =1.0 \times 10^{41} \mathrm{~kg}
\end{aligned}
$$

b. number of stars = total galaxy mass/mass per star

$$
\begin{aligned}
& =\left(1.0 \times 10^{41} \mathrm{~kg}\right) /\left(2.0 \times 10^{30} \mathrm{~kg}\right) \\
& =5.0 \times 10^{10} \\
& =\hookrightarrow(\mathrm{GM} / \mathrm{r}) \\
& =\hookrightarrow\left[\left(6.6 .7 \times 10^{-11} \mathrm{Nm}^{2} / \mathrm{kg}^{2}\right)\left(1.0 \times 10^{41} \mathrm{~kg}\right) /\left(2.2 \times 10^{20} \mathrm{~m}\right)\right] \\
& =1.7 \times 10^{5} \mathrm{~m} / \mathrm{s}=6.1 \times 10^{5} \mathrm{~km} / \mathrm{h}
\end{aligned}
$$

c. $\mathrm{v}=\bullet(\mathrm{GM} / \mathrm{r})$

4. $\mathrm{F}=\mathrm{Gm}_{\mathrm{T}} \mathrm{m}_{\mathrm{S}} / \mathrm{d}^{2}=\left(6.67 \times 10^{-11} \mathrm{Nm}^{2} / \mathrm{kg}^{2}\right)(70.0 \mathrm{~kg})(50.0 \mathrm{~kg}) /(20.0 \mathrm{~m})^{2}$

$$
=5.84 \times 10^{-10} \mathrm{~N}
$$

5. $\mathrm{g}=\mathrm{F} / \mathrm{m}$ so $\mathrm{F}=\mathrm{mg}=(45.0)(7.83)=352 \mathrm{~N}$ 


\section{Example Traditional Unit Test Problems}

From Merrill Physics: Principles and Problems

1. Astronauts in an orbiting space shuttle experience a sensation of weightlessness because

a) the space shuttle is falling freely toward Earth

b) the space shuttle is not affected by Earth's gravity

c) the mass of the space shuttle decreases as the distance from Earth increases

d) the space shuttle is moving away from Earth

2. Earth is closer to the sun in December than it is in July. What happens to the orbital speed of the planet between July and December? Explain your answer.

3. The mass of Jupiter is approximately 318 times that of Earth. Yet, the surface gravity of Jupiter is lass than three times the surface gravity of Earth. How do you account for this apparent discrepancy?

4. Two spheres, each having a mass of $20.0 \mathrm{~kg}$, are positioned so that their centers are $8.00 \mathrm{~m}$ apart. What is the gravitational force between the spheres?

5. The distance between Earth and the sun is often expressed as one astronomical unit (AU). Using this unit, find the distance between the sun and Mars, which has a period of approximately 686 Earth days. 


\section{Answer Key to Example Traditional Unit Test Problems}

1. A. Students would receive 1 point for correct answer

2. The orbital speed of Earth increases between July and December. During this period, Earth is moving closer to the sun, and the closer a planet is to the sun, the faster the planet moves in its orbit.

Students would receive 1 point for correctly indicating increased speed, 2 additional points for correct explanation.

3. The surface gravity of each planet is inversely related to the square of the radius of the planet. Jupiter's radius is much (almost 11 times) greater than Earth's radius.

Students would receive 2 points for correct explanation.

4. $\mathrm{F}=\mathrm{Gm}_{1} \mathrm{~m}_{2} / \mathrm{d}^{2}$

$=\left(6.67 \times 10^{-11} \mathrm{Nm}^{2} / \mathrm{kg}^{2}\right)(20.0 \mathrm{~kg})(20.0 \mathrm{~kg}) /(8.00 \mathrm{~m})^{2}$

$=4.17 \times 10^{-10} \mathrm{~N}$

Students receive 1 point for correct formula, 2 points for correctly using formula, 2 points for correct answer with correct units.

5. $\mathrm{r}_{\mathrm{m}}{ }^{3}=\left(\mathrm{T}_{\mathrm{m}} / \mathrm{T}_{\mathrm{E}}\right)^{2}(1.0 \mathrm{AU})^{3}$

$=(686 \text { days } / 365 \text { days })^{2}(1.0 \mathrm{AU})^{3}$

$=1.52 \mathrm{AU}$

Students receive 1 point for correct formula, 2 points for correctly using formula, 2 points for correct answer with correct units. 


\section{Appendix H}

\section{Post-Graduation Questionnaire}

Hi everybody! :) I hope everything is going well for all of you! I sure do enjoy hearing how all of you have been doing. We keep getting lots of snow up here; the kids love it because it's deeper than they are tall in some places! :)

I'm sending all of you my survey, please fill it out the best that you can. Don't worry, I won't be offended if you say that my class was not your favorite! :) I haven't been able to get in contact with the following people (some I have emails for, but they didn't respond). If anyone has an email for anyone on the list, would you please forward this to them. :) [List of student's names here]

1. Name (your name will not be used):

2. Are you a full-time student, part-time, or not in school?

3. Where do you go to school?

4. What classes are you currently taking? If you are not currently enrolled, what were the last classes that you took?

5 . What is your major? Minor?

6. When do you expect to graduate?

7. What are your plans after graduation?

8. Are you currently working? Where? Doing what? How many hours?

9. What do you see yourself doing in 5 years? 10 years?

10. What did you want to be as a child?

11. What did you want to be after graduating from High School?

12. What was your favorite class in high school? Why?

13. What was your least favorite class in high school? Why?

14. Do you feel that math is important to your life? Why or why not?

15. Do you feel that science is important to your life? Why or why not?

16. What was your favorite part of physics class? Why?

17. What was your least favorite part of physics class? Why?

18. What was your favorite part of math class? Why?

19. What was your least favorite part of math class? Why?

20. What was your favorite and least favorite part of building the bridges? Why?

21. Did doing the bridge project make physics more or less interesting? How?

22. Do you think that learning physics (or any class) through projects makes it easier to understand? Why or why not?

23. What is the best shape to form trusses for the greatest stability?

24. Name three types of bridges.

25. Name 3 people who would be involved in building a bridge and explain how they are involved.

26. When calculating forces on the bridge members, how can you tell when the member is in tension?

27. What is the name of the point where 2 or more members meet?

That's it!!! Don't worry if you can't remember the answer to some of those. Just guess! :) 


\section{Post-Graduation Questionnaire- Answer Key for questions 23, 24, 25, 26,}

and 27

23. What is the best shape for a truss?

Triangular is the best shape for a truss.

24. Name three types of bridges other than a Truss bridge.

Example answers might include Suspension, Girder, Cable Stay, Deck, Arch.

25. Name three people who would be involved in building a bridge and explain how they might be involved.

Example answers would be Engineer, Bank, Project Manager, Owner

(Community), Insurance Agency, Contractor, Government... with explanations of involvement.

26. When calculating forces on bridge members, how can you tell when the member is in tension? The force equals a positive number.

27. What is the name of the point where 2 or more bridge members meet? The place where two or more members meet is called a Joint.

\section{Post-Graduation Questionnaire Grading Rubric: 9 points possible}

23. 1 point possible: 1 point given for correct shape

24. 3 points possible: 1 point given for each correct bridge type up to 3 points

25. 3 points possible: 1 point given for each person(s) with correct explanation up to 3 points

26. 1 point possible: 1 point given for correct answer

27. 1 point possible: 1 point given for correct answer 


\section{Appendix I}

\section{Data for 34 Students}

\begin{tabular}{|c|c|c|c|}
\hline Student & Pretest & Bridge Posttest & Traditional Test \\
\hline $\mathrm{A}$ & 0 & 74 & 71 \\
\hline B & 8 & 79 & 76 \\
\hline $\mathrm{C}$ & 17 & 81 & 80 \\
\hline Kim & 33 & 99 & 73 \\
\hline $\mathrm{D}$ & 17 & 92 & 89 \\
\hline $\mathrm{E}$ & 25 & 78 & 79 \\
\hline $\mathrm{F}$ & 8 & 91 & 88 \\
\hline Jill & 0 & 72 & 50 \\
\hline Ken & 25 & 88 & 80 \\
\hline G & 8 & 71 & 66 \\
\hline $\mathrm{H}$ & 0 & 77 & 73 \\
\hline I & 0 & 63 & 60 \\
\hline Tom & 17 & 83 & 70 \\
\hline $\mathrm{J}$ & 8 & 69 & 63 \\
\hline $\mathrm{K}$ & 8 & 76 & 69 \\
\hline Don & 17 & 70 & 67 \\
\hline $\mathrm{L}$ & 0 & 78 & 71 \\
\hline Matt & 17 & 94 & 65 \\
\hline Sam & 8 & 72 & 75 \\
\hline M & 0 & 73 & 70 \\
\hline $\mathrm{N}$ & 0 & 62 & 48 \\
\hline Ann & 8 & 81 & 77 \\
\hline $\mathrm{O}$ & 17 & 86 & 83 \\
\hline Mark & 17 & 84 & 91 \\
\hline $\mathrm{P}$ & 25 & 82 & 85 \\
\hline Beth & 0 & 76 & 74 \\
\hline Sue & 17 & 76 & 83 \\
\hline Q & 0 & 70 & 52 \\
\hline $\mathrm{R}$ & 17 & 92 & 73 \\
\hline $\mathrm{S}$ & 8 & 71 & 72 \\
\hline $\mathrm{T}$ & 17 & 100 & 93 \\
\hline $\mathrm{U}$ & 17 & 87 & 89 \\
\hline V & 25 & 84 & 77 \\
\hline Ben & 0 & 72 & 65 \\
\hline Median & 8 & 78 & 73 \\
\hline Range & 33 & 38 & 45 \\
\hline Mean & 11 & 80 & 73 \\
\hline Std. Dev. & 7 & 9 & 11 \\
\hline
\end{tabular}

